\author{
Serkan Ekinci \\ Mustafa Alvar
}

http://dx.doi.org/10.21278/brod68209

ISSN 0007-215X

eISSN $1845-5859$

\title{
HORIZONTAL AXIS MARINE CURRENT TURBINE DESIGN FOR WIND-ELECTRIC HYBRID SAILING BOAT
}

UDC 629.535:621.224

Original scientific paper

\begin{abstract}
Summary
In recent decades, the number of theoretical studies and applications on electric power production from renewable sources such as wind, solar, sea and tidal flows, has been increasing rapidly. Marine Current Turbines (MCTs), among the power turbines, produce power from alternating flows and are a means of power production even at lower flow rates in oceans and seas.

In this study, while maintaining functional requirements, an initial and detailed design (mechanic and hydrodynamic), of an MCT fixed on a sailing boat and at sail which extracts power from the flow around the boat, is undertaken. In the design stages, for analysis and optimization of the marine turbine blade design, the Momentum Blade Element Method is utilized. The Horizontal Axis Marine Turbine (HAMT), determined by the initial and mechanical design, is illustrated with its components included. Computational fluid dynamics (CFD) analyses, covering turbine pod geometry at required flow rates and turbine speeds are performed. These analyses are performed very close to real conditions, considering sailing with and without the turbine running (on and off states). The alternator is determined from the results, and the final design which meets the design requirements, is obtained.

As a result, a user friendly and innovative turbine design for sail boats, offering more power and efficiency, which is longer lasting compared to solar and wind technologies, that also makes use of renewable sources, such as wind and/or solar, and in addition stores and uses accumulated energy when needed, is proposed.
\end{abstract}

Key words: $\quad$ Renewable energy; marine current turbine; momentum blade element method; computational fluid dynamics;

\section{Introduction}

Since apparent damage from fossil fuels to the environment has been observed and conventional energy sources are depleting, the trend to use renewable sources of energy is growing day by day. Wind energy, solar energy, and hydrokinetic energy, as well as the conversion of potential energy and motion on the earth into energy, are major forms of renewable energy sources. All these renewable energy sources are alternative sources needed to solve one of the major problems on earth, growing energy demand and the corresponding environmental pollution. Alternative methods to convert potential energy and motion on the earth into energy, include systems converting wave energy present on the sea surface into 
electricity. Probably the most appealing system is the one called "Pelamis". This system involves floating cylinders, positioned one after another, and wave motion-induced changes in pressure in the hydraulic cylinders at the floating cylinder connections are converted into mechanical energy and finally into electricity (Yemm et al. [1]).

Conversion of kinetic energy present in underwater currents into electricity via water turbine is another method of hydro-energy sources. Besides underwater currents, these turbines are also used in the conversion of the flow of energy such as in rivers and straits into electricity. In the literature, a variety of studies in this field can be found. Besides designs similar to conventional wind turbines, designs of various types, varying by place of use, flow characteristics and innovation, are present. Frequently, studies on the turbines for these systems cover the horizontal axis and vertical axis turbines.

MCTs convert flow energy from underwater currents in the sea induced by differences in temperatures, currents induced by tides, and underwater currents occurring in rivers and channels, into electricity. Recently, the number of theoretical and experimental studies on MCTs in the renewable energy and hydrodynamics literature has been increasing. At the beginning of the turbine design is the selection of the hydrofoil section profile. Grasso [2] designed and optimized hydrofoil section profiles for MCTs by referring to the requirements applying to aerofoil sections, the cavitation phenomenon, and water density for flow problem, and proposed new hydrofoil section profiles for MCTs. For wind turbines, wind speeds increase up to $10-15 \mathrm{~m} / \mathrm{s}$, while in MCTs flow rates of up to $4-5 \mathrm{~m} / \mathrm{s}$ are considered. In the present study, the flow rate in a turbine is considered to be equal to the ship's speed at sail. Low flow rates result in reduced Reynolds numbers calculated over the hydrofoil section. For this reason, for selection of the hydrofoil section profile, sections yielding high performance at low Reynolds numbers should be considered. Somers and Moughmer [3] conducted studies and theoretical aerodynamics analyses on the application of section profiles of various types on small scale wind turbines at the National Renewable Energy Laboratory (NREL). Ahmed [4] investigated six different section profiles for turbines at low Reynolds numbers. In general, MBEM, known as the enhanced version of actuator disc theory, is used to design, to evaluate calculated performance and, accordingly, geometrical optimization, and to determine the final geometry for wind and current turbines. The MBEM is a combined form of momentum theory and blade element theory. In the initial design stage of turbines, MBEM is the frequently preferred method, being fast and user friendly. Batten et al. [5] investigated the hydrodynamic design of MCTs. Considering performance, MBEM is considered adequate for turbine blade designs with short chord lengths at uniform flow conditions. The effect of blade pitch and camber characteristics of the section profile on performance is investigated. In another study, Batten et al. [6] conducted cavitation tests of a turbine model calculated at scale model. Results obtained from theoretical calculations are shown to be consistent with the test results. Chen et al. [7] developed turbine designs for applications for places such as shallow waters around an island and rivers. NACA63-415 profile is considered in the study. Performance of the initial design of the turbine by MBEM, and in particular, the effect of the blade tip chord width on performance were investigated. Designing the initial turbine by MBEM, and afterwards, performing detailed design and verification studies using CFD are essential for obtaining final turbine geometry. Lee et al. [8] investigated the results from MBEM and CFD analyses and compared them with the model test results of a turbine. At the detailed design stage, the camber values of turbine blade geometry close to the blade tip are varied; the effect on cavitation and performance results is investigated; and the results are evaluated in comparison with CFD results. CFD analyses on a full-scale model can be performed, and turbine operating conditions can be investigated close to actual operating conditions. However, owing to dimension limitations, scaling in tests regarding to turbine 
sizes is applied. However, CFD analyses are done for full scale models and the solution mesh structure is increased, and so the computing time is increased. Mason-Jones et al. [9], investigated the effect of scaling on determining both turbine design and performance. Results from CFD analyses are compared to experiments and full scale model test results. Furthermore, the effect of changes in the velocity profile acting on the turbine is investigated. Wang and Atlar [10] investigated the characteristics of cavitation, noise and slip stream on MCTs, experimentally. MCTs at shallow shaft depths are observed to be under strong and unsteady sheet and cloud cavitation. For large MCTs, in particular, manufacturing cost and performance are significant parameters acting upon investment return periods. Using MBEM, Evans et al. [11] studied changes in turbine blade section thickness on manufacturing cost and performance, and determined the optimum blade geometry. For MCTs, thrust of turbine is important in determining both turbine blade strength and dimensioning of the construction of the turbine foundation used for fixing on the ground. In the present study, since the turbine is installed on the hull, besides performance, the effect of acting thrust on structural design should be considered. For shallow water MCT in use, Fernandez-Rodriguez [12] determined that highest thrust forces can be observed in waves and turbulent flow using MBEM and CFD. For current turbine performance, uniformity of flow passing through the turbine is essential. In addition, the mechanical power train of the turbine, shaft connections, pod, etc., to transfer the power, and the hub details for the blades attached, should be placed as after the turbine blades if possible. However, the flow passing through the turbine is converted into energy and the flow is disturbed by turbine rotation passing downstream which acts on the mechanical parts. This effect is important in turbine design for two reasons. First is the negative effect on turbine performance, occurring when a drop-in pressure causes reduction in flow velocity. So, the distance between mechanical parts to be placed downstream of the turbine and turbine blades is important. Second is the helical wake, downstream of the turbine, developed by turbine rotation which increases the resistance component of the system, compared to straight flow. Frost et al. [13] studied the forces acting on the system, considering the effect of flow properties on the turbine blade axis and the size of the mechanical structure, downstream of the turbine. In the literature, methods used in turbine design and performance calculations, besides MBEM and CFD, are present. Usar and Bal [14] calculated cavitation development in MCTs using a combined method of MBEM and Boundary Element Method (BEM); investigated its effect on performance; and compared the results with test results. Kinnas and $\mathrm{Xu}$ [15] presented computational methods, i.e. BEM and Vortex Lattice Method (VLM).

Firstly, at the preliminary design stage, according to the requirements for MCT on hull, the turbine blade section profile, blade tip speed ratio (TSR) and turbine diameter are determined. Later on, blade geometry optimization and modeling are done using the software of two different open source codes, based on MBEM. One of these methods is called 'Harp_Opt', and is used for turbine optimization. This code is supported by the National Renewable Energy Laboratory (NREL) and is still being developed [16], [17]. 'QBlade', the other code [19], has a user friendly interface, is based on MBEM, is used for blade geometry modeling, is integrated to XFOIL code [18], and is also used for section profile properties. To calculate performance in the Qblade code, section $C_{L}$ and $C_{D}$ data can be calculated. In addition, turbine blades can be modeled in $3 \mathrm{D}$, and can be exported to other software for further use, and the performance calculations are supported with visual graphics. Initial performance calculations and the effect of turbine blade pitch relative to turbine hub on the design requirements are both investigated using MBEM, and appropriate positions are determined. In the detailed design stage, the mechanical design with respect to the initial design, consisting of turbine hub/pod geometry and system components, is performed. Afterwards, CFD analyses for the final turbine design, including pod geometry, at required 
flow velocities and turbine speeds are performed. The analyses are performed very close to real conditions, considering sailing with and without turbine running (on and off states). The alternator is determined based on the results, and the final design is obtained. Whether the final design meets the design requirements is investigated, and further improvements are discussed.

\section{Momentum blade element method (MBEM)}

Wind turbines and MCTs are designed in similar ways. However, the most interesting difference is that the density of water is 836 times the density of air. Moreover, cavitation formation in water should be considered in the design process. Considering the difference in density, MCTs can be designed using the same calculation methods as wind turbines. In the present study, whether the cavitation phenomenon could possibly occur on the MCT blades is not investigated.

MBEM, developed by Rankine [20] and Glauert [21], is widely used in the design and analysis of wind turbines (Hansen et al. [22]; Maalawi et al. [23]). In MBEM, turbine operation is treated as a combination of two methods. The first method is momentum applied to the turbine and the momentum balance of the rotational cylindrical flow. The second method is the Blade Element Theory for calculation of the lift and drag coefficients of the turbine blade sections. Assumptions used in MBEM are: 1-) No interference among blade elements. 2-) Lifting and drag forces are related to the lift and drag coefficients, calculated for the blade element profile. 3-) Flow is incompressible. 4-) No cavitation occurs. 5-) Forces acting on the blades are related to the section profile characteristics, $C_{L}$ and $C_{D}$. 6-) Blade elements are considered in 2D and no interference occurs in between.

The method is applied to the blade profile in each stream tube, obtained by dividing the propeller into many stream tubes along the propeller radius, by calculating the force balance for the lift and resistance forces and thrust and torque obtained in each tube, and the momentum balance for axial and angular moments (Hansen [24]). As a result, a nonlinear equation system to be solved iteratively for each flow tube is generated. Propeller performance is predicted by integrating element thrust and torque data along the propeller radius (Manwell et al. [25]) and power output can be obtained. The required hydrodynamic performance for MCTs can be modeled similar to wind turbines (Burton et al. [26]; Batten et al. [27]). One of the most probable reasons for application of this method is giving results with high accuracy and in short calculation durations (Whelan et al. [28]; Widjanarko et al. [29]).

Speed distribution on a turbine blade profile is shown in Figure 1, where the vector denoted by $V(1-\alpha)$ is the flow velocity under axial flow factor, the vector denoted by $\Omega r+(\omega r / 2)$ is the section angular speed under rotational flow factor, and the resultant velocity vector directed on the blade section is denoted by:

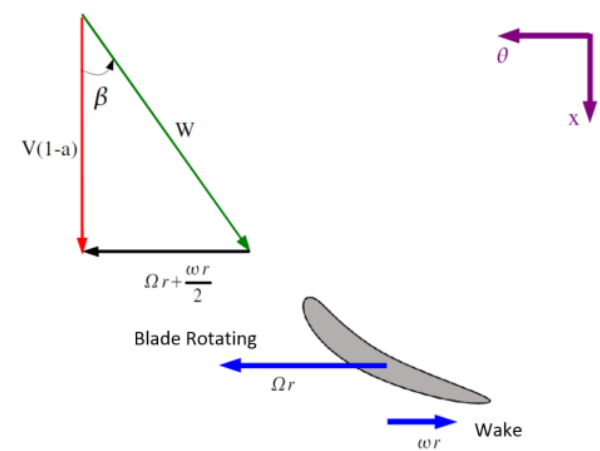

Fig.1 Speed distribution on a turbine blade profile 
Fundamental equations underlying the method to design a turbine and to calculate turbine performance are axial force and torque expressions. The first two equations below denoted by Eq. (1) and Eq. (2), are acquired from the momentum balance and the force and torque expressions. The latter two equations are denoted by Eq. (3) and Eq. (4), calculated from the section profile characteristics, $C_{L}$ and $C_{D}$.

$$
\begin{aligned}
& d F_{x}=Q \rho V_{1}^{2}[4 a(1-a)] \pi r d r \\
& d T=Q 4 a^{\prime}(1-a) \rho V \Omega r^{3} \pi d r
\end{aligned}
$$

here ;

$$
\begin{aligned}
& O=\frac{2}{\pi} \cos ^{-1}\left[\exp \left\{-\left(\frac{B\left[\frac{B}{2\left[\frac{r}{R}\right]}\right)}{\left(\frac{r}{R}\right) \cos \beta}\right\}\right]\right. \\
& d F_{x}=\sigma^{\prime} \pi \rho \frac{v^{2}(1-a)^{2}}{\cos ^{2} \beta}\left(C_{L} \sin \beta+C_{D} \cos \beta\right) r d r \\
& T=\sigma^{\prime} \pi \rho \frac{v^{2}(1-a)^{2}}{\cos ^{2} \beta}\left(C_{L} \cos \beta-C_{D} \sin \beta\right) r^{2} d r \\
& \sigma^{\prime}=\frac{B c}{2 \pi r}
\end{aligned}
$$

Equating the above equations, the equations used in the turbine performance calculations can be obtained as follows.

$$
\begin{aligned}
& \frac{a}{1-a}=\frac{\sigma^{\prime}\left[C_{L} \sin \beta+C_{D} \cos \beta\right]}{4 Q \cos ^{2} \beta} \\
& \frac{a^{\prime}}{1-a}=\frac{\sigma^{\prime}\left[C_{L} \cos \beta-C_{D} \sin \beta\right]}{4 Q \lambda_{r} \cos ^{2} \beta}
\end{aligned}
$$

Another ratio used in turbine performance calculations is the Tip Speed Ratio (TSR) and is denoted by $\lambda_{r}$. As is given in Eq. (8), the TSR is defined as the ratio of blade section rotational speed to flow velocity passing through the turbine, at any radius.

$\lambda_{r}=\frac{\Omega r}{V}$

Another parameter used in turbine performance calculations is the power coefficient, $C_{p}$. Total power produced by the turbine is expressed using each blade element in the corresponding section, as given in Eq. (9) in common form.

$d P=\Omega d T$

When this equation is integrated over the blade, the expression for the total power equation given by equation (10) is obtained.

$P=\int_{r_{h}}^{R} d P d r=\int_{r_{h}}^{R} \Omega d T d r$

- where, $r_{h}$, is the turbine hub radius. The power coefficient, $C_{p}$, is given in Eq. 11.

$C_{P}=\frac{8}{\lambda^{2}} \int_{\lambda_{h}}^{\lambda} Q \lambda_{r}^{3} a^{\prime}(1-a)\left[1-\frac{C_{D}}{C_{L}} \tan \beta\right] d \lambda_{r}$ 
For detailed information on MBEM, a prior study by Usar and Bal [14] can be surveyed.

Turbine design is based on profile section performance and is related to turbine efficiency. To maximize power output of the turbine, the hydrodynamic lifting force should be at a maximum, but the drag (resistant) force should be at a minimum. Therefore, in profile section selection, the ratio of the lifting coefficient to drag coefficient, $C_{L} / C_{D}$, should be determined as high. In the present study, empirical expressions for the pitch, $(\beta)$ and chord length, $(c)$, are defined in order to evaluate, especially, the turbine diameter and number of blades with respect to common design requirements. The Shmitz method is used for this. According to Shmitz, since $C_{L}$ is known, the section pitch, $(\beta)$, and chord length, $(c)$, can be determined by Eq. (12) and Eq. (13), respectively.

$$
\begin{aligned}
& \beta(r)_{\text {shmitz }}=\frac{2}{3} \arctan \frac{R}{r \lambda}-\alpha_{D} \\
& c(r)_{\text {shmitz }}=\frac{1}{B} \frac{16 \pi r}{C_{L}} \sin ^{2}\left(\frac{1}{3} \arctan \left(\frac{R}{\lambda r}\right)\right)
\end{aligned}
$$

\section{Determination of turbine general characteristics (initial design)}

In this study, the design of an MCT, placed on a Zero Emission Renewable Energy Producing Sail Boat (REPSAIL) as the primary renewable energy source, is presented. In the REPSAIL concept, electricity is produced while sailing by wind energy, solar energy and/or sail using water flow developed around the hull, and is stored, and then, when needed, accumulated electricity is used for propulsion and life support systems (profile view in Figure 2 and perspective view in Figure 3). In concept design, at sail or at anchor, wind turbines which produce electricity from wind energy and solar panels placed on a superstructure to maximize panel area, are present. However, in the present study detailed information on wind turbine and solar panels are not given.
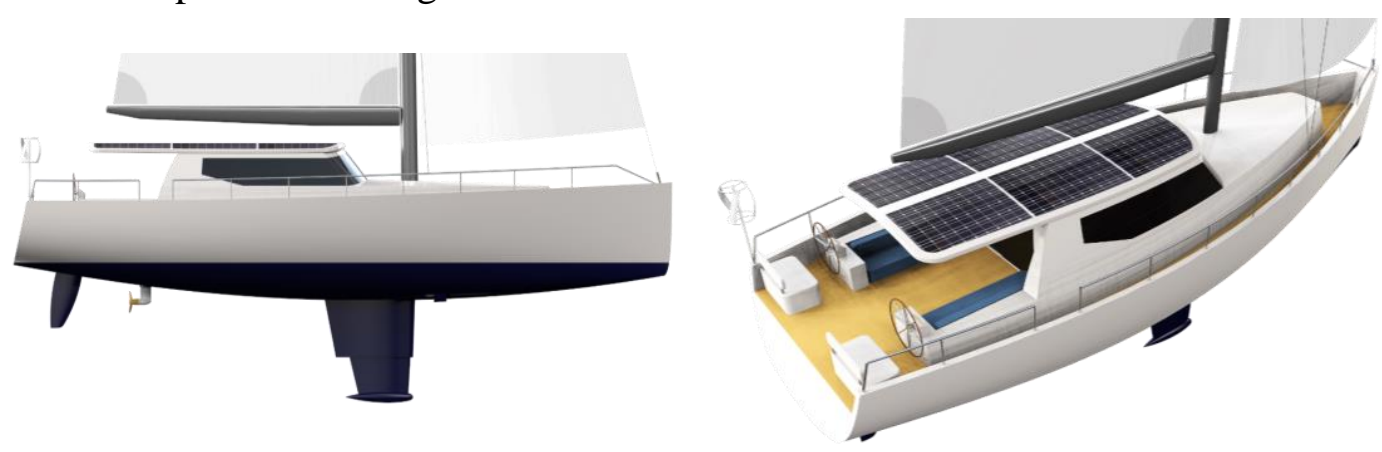

Fig.2 A profile view related to REPSAIL project

Fig.3 A perspective view related to REPSAIL project

Design criteria for the horizontal MCT on a vessel are as follows: 1-) Two turbines should be installed on the vessel, one on the starboard and one on the port. 2-) Turbine sizing, diameter, length, etc., should be determined by the designer, and in common turbines, the diameter should be regarded as being below $700 \mathrm{~mm}$ for the visual aspects. 3-) Turbine longitudinal and transverse positions should be determined considering the interior layout, in flow interference among turbines and other appendages such as propulsion system and keel. 4-) While turbines are running, at sail, developed added resistance caused by friction and thrust, should not exceed $25 \%$ of hull resistance. 5-) Design point should be considered as 3.1 $\mathrm{m} / \mathrm{s}$ (6 knot). 6-) Turbine, while not in use, should be designed to cause minimum resistance. 7-) At design point, a $3.1 \mathrm{~m} / \mathrm{s}$ turbine should be designed to produce electric power of $850 \mathrm{~W}$, at least. 8-) Turbine should start to produce electricity not exceeding vessel speed of $2.5 \mathrm{~m} / \mathrm{s}$ 
(4.8 knot). Produced electricity should be not less than $300 \mathrm{~W}$. 9-) Weight of one turbine, including alternators up to main power management system connection, should not exceed 35 kg. 10-) Throughout the turbine design, sea water resistant materials should be used. 11-) Turbine installation on the vessel should be designed to be watertight.

\subsection{Determination of blade section profile}

In determining section profiles, sample profiles used in wind turbines for low Reynolds number $\left(R_{e}\right)$ are considered (Figure 4$)$. When compared to wind turbines, the flow velocities of MCTs are low, and consequently, have similar $R_{e}$ numbers, and so similar profile types can be used (Sale [30]). However the density of water is much higher than air.

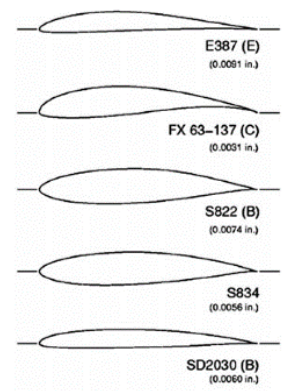

Fig.4 Sample profiles for low Reynolds numbers

Ratios of $C_{L} / C_{D}$ for considered profiles are calculated and shown in Figure 5, comparatively. FX63-137 profile with the highest ratio is determined. The profile determined is the first profile designed for a human powered air vehicle with the lowest $R e$ number. The original name of the profile is "Wortmann FX63-137". While having a quite thin trailing edge makes manufacturing difficult, this doesn't have much influence on performance. Thus, considering the feasibility of manufacture, the trailing edge is modified and throughout the rest of the calculations, modified profile properties are used.

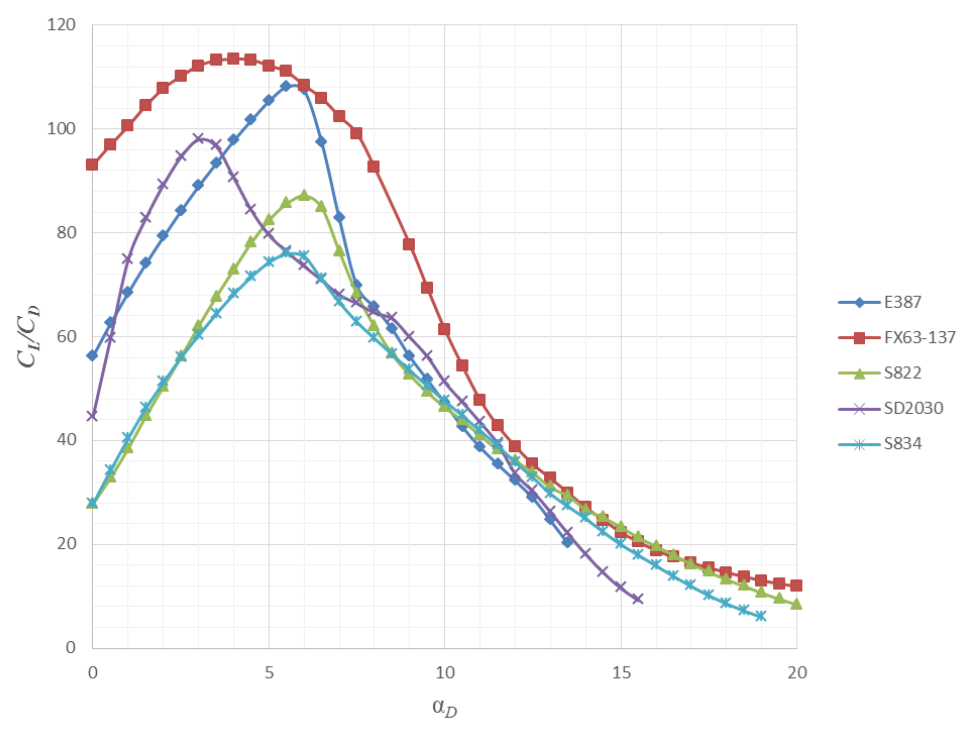

Fig. 5 Ratios of $C_{L} / C_{D}$ for considered profiles

In Figure 6, the considered original FX63-137 profile, and in Figure 7 FX63-137 profiles with modified trailing edge in order to obtain the new geometry, to be used in the turbine design are shown. Comparison of the $C_{L}$ and $C_{D}$ values for both FX63-137 profiles, original and with modified trailing edge are shown in Figure 8. 


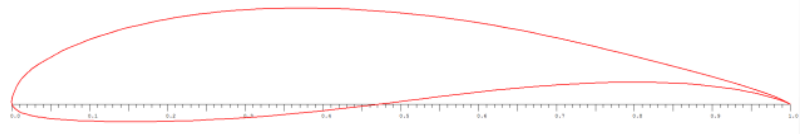

Fig. 6 FX63-137 profile (original)

Fig. 7 FX63-137 profile (with modified trailing edge)
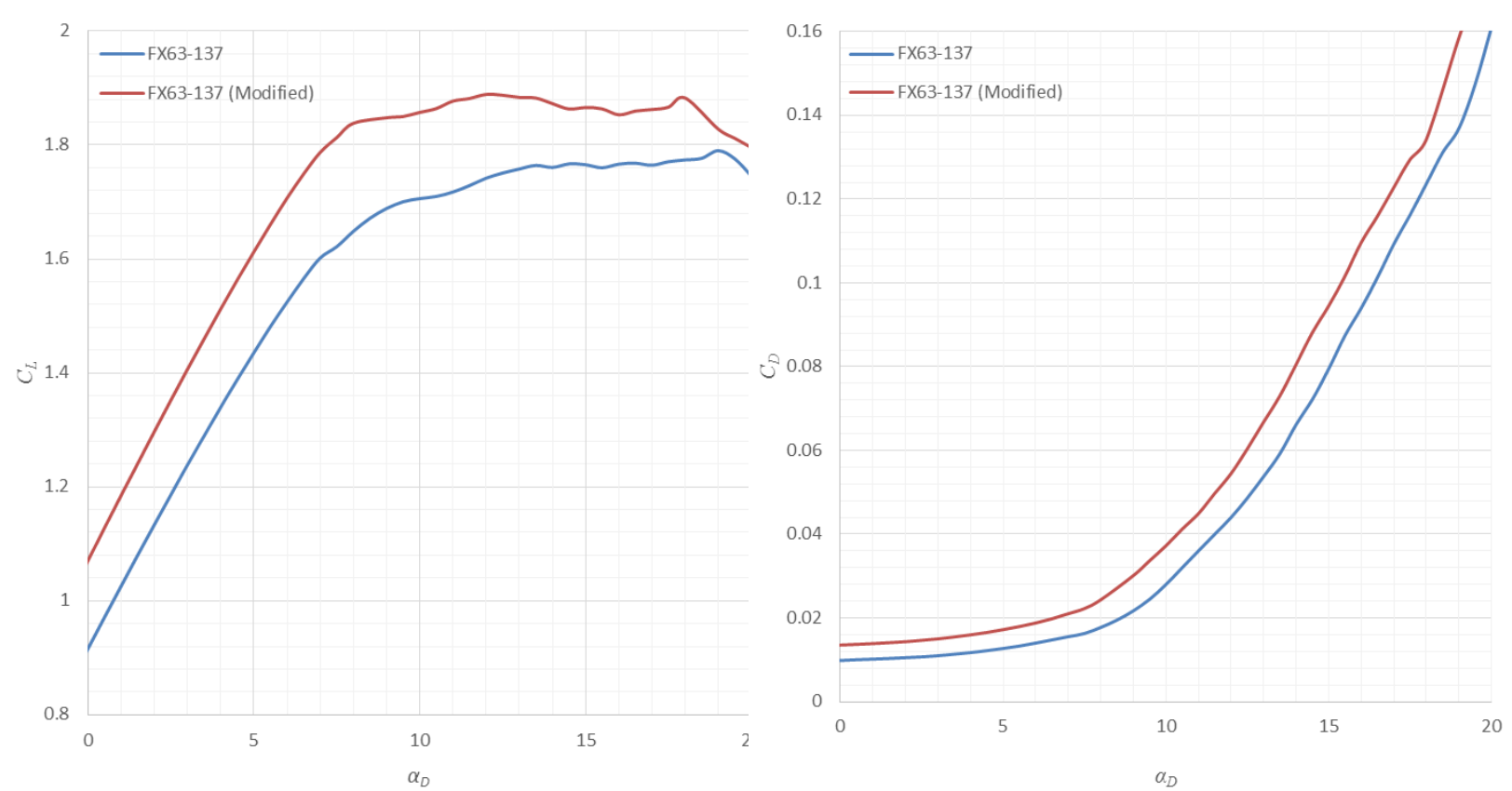

Fig. $8 C_{L}$ and $C_{D}$ values of FX63-137 profiles (original and with modified trailing edge)

\subsection{Determination of blade tip speed ratio and blade number}

In turbine design, TSR is used frequently to reveal and present operation points with the highest efficiency for the vessel, and the aim is to convert the water flow developed around the hull into energy by the turbine. Throughout the process, appendage geometry on the hull causes extra resistance. Inevitably, the added resistance reduces vessel speed. At this point, the goal is to minimize this effect and develop the most efficient system. Considered appendage resistance on the hull is caused by two different hydrodynamic forces. The first force is viscous resistance components caused by flow through the turbine geometry and the other is the force acting to slow the vessel, since the developed thrust, caused by rotation on the turbine blades is opposite the vessel direction of movement. The thrust under consideration increases with respect to the increase in the number of revolutions. Therefore, in the study, low TSR value selection is considered to be more convenient and sample MCTs with different TSRs produced for this purpose are investigated and corresponding characteristics are listed in Table 1. When data in the list are reviewed, the ratio of diameter to number of revolutions is seen to be almost constant. Using this ratio, TSR can be predicted by determining the possible number of revolutions for the corresponding turbine diameters. Initial calculation at the preliminary stage is performed for 5 turbine diameters in the range of $0.3-0.7 \mathrm{~m}$. So, for the design point of $3.1 \mathrm{~m} / \mathrm{s}$, the turbine speeds and TSRs corresponding to the number of 
revolutions, are calculated using the ratio of diameter to number of revolutions, and the number of revolutions for the design point of $3.1 \mathrm{~m} / \mathrm{s}$ for the diameters ranging from 0.3 to 0.7 $\mathrm{m}$ is given in Table 2. The TSR values for the 5 turbine blades are found to be around 3.4, and this number is used in the initial design calculations. The number of blades is determined according to the TSR number from related studies in this field. In the present study, the number of blades according to the TSR number is considered as 3 .

Table 1. Characteristics for sample marine current turbines with different TSRs

\begin{tabular}{|l|l|l|l|l|l|l|}
\hline Nominal flow speed $(\mathrm{m} / \mathrm{s})$ & 2.00 & 2.50 & 3.00 & 3.50 & 4.00 & 4.50 \\
\hline Diameter of turbine $(\mathrm{m})$ & 6.30 & 5.10 & 4.40 & 3.80 & 3.40 & 3.10 \\
\hline Area of turbine $\left(\mathrm{m}^{2}\right)$ & 31.20 & 20.40 & 15.00 & 11.50 & 9.30 & 7.70 \\
\hline Nominal power $(\mathrm{kW})$ & 42 & 55 & 66 & 78 & 88 & 98 \\
\hline Nominal rotation speed $(\mathrm{rpm})$ & 32.20 & 39.00 & 46.00 & 52.00 & 58.00 & 64.00 \\
\hline TSR & 5.31 & 4.17 & 3.53 & 2.96 & 2.58 & 2.31 \\
\hline Diameter/rotation speed ratio & 10.62 & 10.41 & 10.60 & 10.35 & 10.33 & 10.39 \\
\hline
\end{tabular}

\subsection{Determination of turbine diameter}

To determine the turbine diameter, performance data for 5 turbines with diameters in the range of 0.3-0.7 $\mathrm{m}$, are calculated and listed in Table 2. Considering the design requirements, the thrust of alternative turbines with $0.6 \mathrm{~m}$ and $0.7 \mathrm{~m}$ diameters exceeds permissible turbine thrust, and the thrust of alternative turbines with $0.3 \mathrm{~m}$ and $0.4 \mathrm{~m}$ diameters, are inadequate in potential power production. Therefore, turbine with $0.5 \mathrm{~m}$ diameter potentially produce power sustaining $1357 \mathrm{~W}$, regarding no losses, is considered the most convenient. Consequently, the turbine diameter is determined as $0.5 \mathrm{~m}$. However, in the thrust aspect, this diameter yields higher than design requirements, so this value can be reduced in the detailed design stage using CFD analysis results.

Table 2 Performance evaluation for turbine designs ( $\mathrm{D}=0.3-0.7)$

\begin{tabular}{|c|r|l|l|l|l|l|}
\hline $\begin{array}{l}\text { Turbine } \\
\text { Diameter } \\
(\mathrm{m})\end{array}$ & $\begin{array}{l}\text { Flow } \\
\text { speed } \\
(\mathrm{m} / \mathrm{s})\end{array}$ & TSR & $\begin{array}{l}\text { Nominal } \\
\text { rotation } \\
\text { speed(rpm) }\end{array}$ & $\begin{array}{l}\text { Power } \\
(\mathrm{W})\end{array}$ & $\begin{array}{l}\text { Thrust } \\
(\mathrm{N})\end{array}$ & $\begin{array}{l}\text { Torque } \\
(\mathrm{Nm})\end{array}$ \\
\hline 0.3 & 3.1 & 3.4 & 675 & 485.5 & 282.7 & 6.91 \\
\hline 0.4 & 3.1 & 3.4 & 506 & 865.5 & 501.5 & 16.45 \\
\hline 0.5 & 3.1 & 3.4 & 405 & 1357 & 782.5 & 32.2 \\
\hline 0.6 & 3.1 & 3.4 & 338 & 1957.5 & 1126 & 55.7 \\
\hline 0.7 & 3.1 & 3.4 & 290 & 2668 & 1530 & 88.7 \\
\hline
\end{tabular}

\section{Detailed design}

The diameter, $0.5 \mathrm{~m}$, and TSR, 3.4, obtained in the previous section are input data for geometric optimization in the design stage. At this stage, horizontal axis wind/current turbine optimization is performed using HARB_Opt, developed by Sale [30, 31] as an open source code that is a combination of multi-purpose genetic algorithm and MBEM. In HARB_Opt, performance calculations are performed using MBEM and design multi criteria optimization is performed using MATLAB genetic algorithm solver. Also, MCT calculations can be performed in HARB_Opt. Another specification of HARB_Opt is the calculation of cavitation formation on blade sections using a dimensionless pressure coefficient, $C_{P r}$. And later cavitation formation is used in determining blade pitch, , $\beta$ and chord length, $c$. However, this code specification is not used since turbine operational dynamics and design requirements 
considered in the study differ from the MCTs. In determining the above mentioned data, blade geometry is optimized according to design requirements. Using the code, turbine blade geometry section pitches and chord distributions at design points are optimized, sustaining TSR. Afterwards, geometrical modeling is performed in QBlade code, using obtained results. QBlade is a code developed to evaluate design and performance calculations for wind turbines, and is still being developed. QBlade includes XFOIL blade section profile calculation code, and calculated blade section profile characteristics can be directly used in MBEM calculations. At this stage, blade pitch according to design requirements is evaluated; geometrical design is finalized; and performance indices in the final situation are calculated. Common input data for optimization in HARB_Opt are listed in Table 3.

Geometrical boundaries for optimization can be defined in HARB_Opt. In the present study, the lowest value is limited only for chord lengths. The reason is to maintain manufacturability of the blades. Thicknesses along the determined section profile change with chord length, and the thinnest region occurs at the trailing edge. In the corresponding calculations, the thickness of trailing edge is found to be $1 \mathrm{~mm}$ for a chord length of $37 \mathrm{~mm}$. The considered blades are manufactured with machining and, as maintaining manufacturing lengths below $1 \mathrm{~mm}$ is difficult, manufacturing tolerances are going to be higher. Therefore, minimum chord lengths at the blade tips are kept at $37 \mathrm{~mm}$.

Table 3 Optimization variables in HARB_Opt

\begin{tabular}{|l|l|}
\hline OPTIMIZATION VARIABLES & \multicolumn{1}{c|}{ ELECTIONS } \\
\hline Turbine speed control method & variable speed \\
\hline Turbine pitch control method & constant pitch \\
\hline Blade number & 3 \\
\hline Maximum rotation speed & $850[\mathrm{rpm}]$ \\
\hline Theoretical power & $6000[\mathrm{w}]$ \\
\hline Blade element number & 30 \\
\hline Minimum flow speed & $0.5(\mathrm{~m} / \mathrm{s})$ \\
\hline Maximum flow speed & $5.1(\mathrm{~m} / \mathrm{s})$ \\
\hline Blade section profile & FX63-137(modified) \\
\hline Limit of minimum chord length (in blade tip) & 37 mm \\
\hline
\end{tabular}

In Table 4, optimized blade geometric properties are given. Optimized geometry is modeled in QBlade code, and shown as a single blade form in Figure 9. In optimization using HARB_Opt, TSR is found as 3.88, and the corresponding power coefficient, $C_{P}$, is 0.46 . The $C_{P}$ - TSR graph for the optimized geometry in Q-Blade is shown in Figure 10.

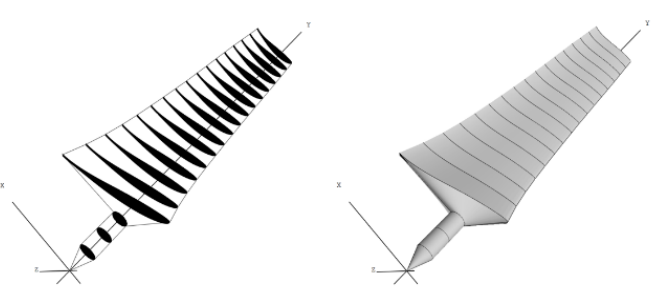

Fig. 9 Optimized geometry (single blade) 
Table 4 Optimized blade geometric properties

\begin{tabular}{|l|c|c|c|c|c|c|c|c|c|c|}
\hline $\mathrm{r} / \mathrm{R}$ & 0.2 & 0.3 & 0.4 & 0.5 & 0.6 & 0.7 & 0.8 & 0.9 & 0.95 & 1 \\
\hline $\mathrm{r}[\mathrm{mm}]$ & 50 & 75 & 100 & 25 & 150 & 175 & 200 & 225 & 237.5 & 250 \\
\hline $\mathrm{c}[\mathrm{mm}]$ & 76.5 & 60.8 & 54.7 & 51.2 & 48.4 & 46.6 & 45.2 & 43.3 & 42.2 & 41.5 \\
\hline$\beta[$ degree $]$ & 34.1 & 25.7 & 21.9 & 19.3 & 17.2 & 15.3 & 13.4 & 11.1 & 9.7 & 8.5 \\
\hline
\end{tabular}

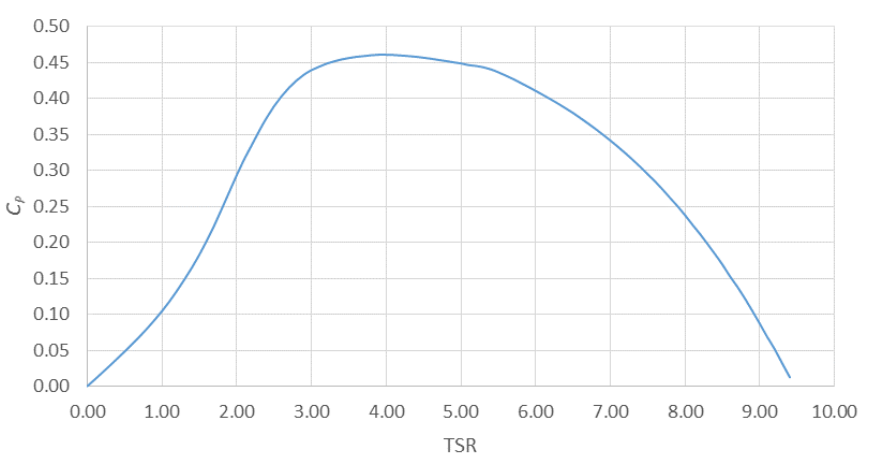

Fig. 10 Computed $C_{P}$-TSR curve for optimized turbine blade geometry

At the design point with a flow velocity of $3.1 \mathrm{~m} / \mathrm{s}$, the turbine speeds (in rpm), thrust (in $\mathrm{N}$ ), torque (in $\mathrm{Nm}$ ) and obtained theoretical power, $\mathrm{P}$, (in $\mathrm{W}$ ) computed from MBEM for optimized turbine blade are given in Table 5. As a conclusion, the designed turbine sustains the power requirements at design velocity; however the developed thrust is over the predictions. Furthermore, the obtained result is above the TSR, determined in the initial design.

Table 5 Performance results computed from MBEM for optimized turbine blade

\begin{tabular}{|c|c|c|c|c|c|c|}
\hline $\begin{array}{c}\text { Flow } \\
\text { speed } \\
(\mathrm{m} / \mathrm{s})\end{array}$ & $\begin{array}{c}\text { Turbine } \\
\text { rotation } \\
\text { speed }(\mathrm{rpm})\end{array}$ & $C_{P}(-)$ & $\begin{array}{c}\text { TSR } \\
(-)\end{array}$ & Torque $(\mathrm{Nm})$ & Thrust(N) & $\begin{array}{c}\text { Theoretical } \\
\text { power(W) }\end{array}$ \\
\hline 3.1 & 460 & 0.461 & 3.88 & 28.72 & 827 & 1383.5 \\
\hline
\end{tabular}

Increase in TSR caused increase in turbine speed. Therefore, thrust on the design should be reduced to levels mentioned in the design requirements and, instead of changing the blade geometry, namely the chord lengths and/or section pitches, changing the blade pitch changes only its degree without any influence on optimized blade performance trend.

\section{Mechanical Design}

At the initial design and detailed design stages, the hydrodynamic designs of the turbine blades are done individually, and performance is evaluated similar to propeller design, as in open water performance calculations. Actually, a turbine operates before a pod, and a specified distance between turbine blade tips and hull is present. On the other hand, in MBEM used at the initial design stage, especially at low flow velocities and low blade number of revolutions, the viscous effect and geometrical interference between the turbine-pod and turbine-hull are not considered in the calculations. It is essential that the calculation method be detailed, considering these effects, to generate results with less error. In order to perform these analyses, apart from the turbine blade geometries (determined at the initial design stage), the hub and pod geometries, connection details between turbine and hull, and turbine position relative to hull geometry are to be determined. Therefore, design of the components composing the turbine system, and those under the influence of flow are presented for CFD analysis, by determining the aforementioned details. A commercial product, Solidworks software [32], is used for the mechanical design. 


\subsection{Hub Design}

Since the vessel is propelled by electric motor using accumulated energy from renewable sources, efficient use of stored energy is essential. Therefore, reducing appendage resistances, besides hull resistance, increases efficiency. Turbines are to be used while sailing, since using turbines for engine sail is inefficient, and keeping turbine position and geometry the same while sailing has a negative influence. So, construction of turbine blades capable of folding, and the necessity to change position at engine sail to reduce flow-induced resistances on the blades is obvious. For this situation, the turbine is designed for two positions. In the first one, the blades are unfolded while the turbines are running (Position 1) and in the second one, the pod rotates 180 degrees to reduce the blade surface area across the flow and the blades are folded (Position 2).

To operate in Position 1, blades are to be movable. When unfolded, the blades resume the design positions, and when folded, the blades reach positions to form the least area across the flow. In operation, the blades are to move in synchronization and share the hydrodynamic force causing movement. For this reason, the blades are designed separately for mounting and are built in contact with each other through a gear system at the hub conjunction. The disadvantage of this design is the extra space required for the hub diameter but in the end the gains are worthwhile. The turbine blades and mounted hub at on state position are shown in Figure 11, and the off state position is shown in Figure 12. Nowadays, blades with foldable form in such a system are used frequently for propulsion on sailboats. Information on this type of propeller can be found in [33].

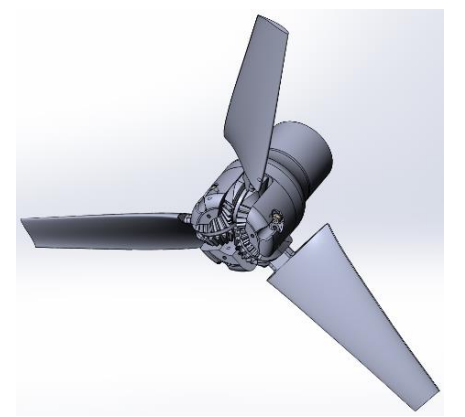

Fig. 11 Mounted hub and blades (Position 1-on state)

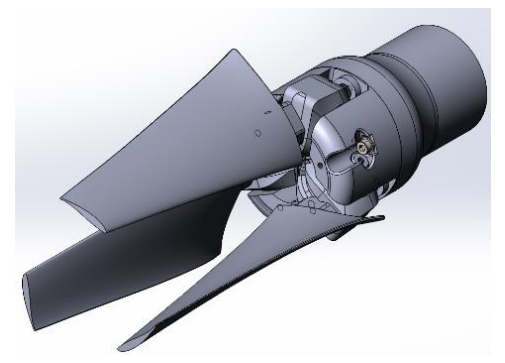

Fig. 12 Mounted hub and blades (Position 2-off state)

\subsection{Pod Design}

To evaluate the performance of the whole system through flow analyses, after hub and propeller-hub connection design, a significant part of the design for flow volume is the pod component. In the pod component geometric design stage, sections with "drop" shaped forms, frequently used in rudder designs, have been preferred. However, a symmetrical section is determined, considering the system to be capable of rotating $180^{\circ}$, so that both leading and trailing edges of the section operate across the flow. In determining the section sizes, the vertical shaft in the center and the corresponding required diameter are considered.

With a $42 \mathrm{~mm}$ tolerance for the vertical shaft at the center and a certain wall thickness, the profile length is determined through a series of $2 \mathrm{D}$ analyses. Where changes in section lift and drag coefficients are observed, the most convenient profile length and tip radii are determined. In the present study, details of the study for determining the section profile stage are not given. For the final section geometry and performed 2D analyses, in particular, at the point of flow normal to the section trailing edge, no noteworthy flow divergences occur. For 
leeway flow, however, the turbulence occurring behind the profile is negative and the same situation is encountered for all tested sections. A dynamic positioning system can regulate the system angle relative to each leeway angle of the vessel. Since a dynamic positioning system considerably raises the complexity and costs, it is not included. The flange at the connection of pod to hull is a support component, which transfers rotational force in the turbine axis through the horizontal shaft, and is mounted among the shaft bearings and speed governor gears. In Figure 13, section and perspective views of the final pod design are shown. In Figure 14, the longitudinal turbine section is shown. Alvar [34] can be referred for section and perspective views of the final pod design be used for details of the mechanical design components.

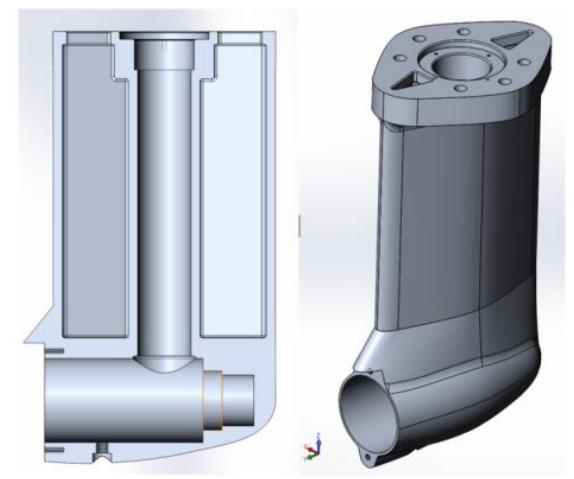

Fig.13 Section and perspective views of the final pod design

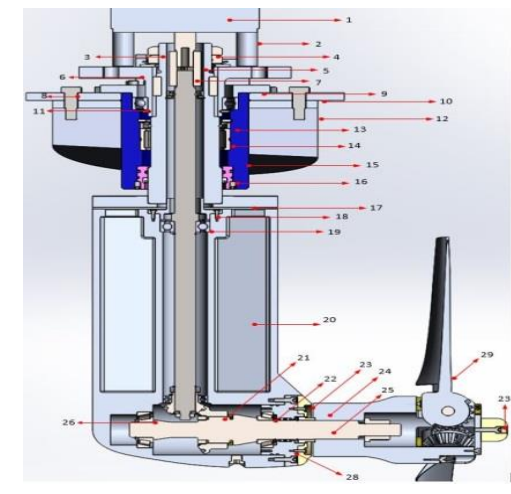

Fig.14 Longitudinal turbine section

Various factors are considered to determine the turbine position on a vessel, namely, the distance between turbine blades and vessel hull, keel position, vessel interior design, trim and list angles occurring at sailing, and turbine operation positions. From the hydrodynamic aspect, uniform flow, passing through the turbine blades, quite close to the vessel speed, maintains ideal performance. Therefore, ideal turbine position is at vessel fore, where the most uniform flow is present. Components that remain in the vessel are position control unit, electrical connections and vessel mounting connections. For system accessibility, closeness to electrical connections and as distant as possible from the cabin space for passengers to rest, are necessary.

On the other hand, the engine room includes the keel arrangement in the vessel. However, while sailing in leeway flows, the keel has the risk of blocking flow through one of the turbines so the turbines are placed before the keel. Distance between turbines is maximized to minimize interference between the turbines; however, distance in between turbines is determined by the limitations of the keel support positions and to limit extension beyond the vessel beam, such as potential entanglement of fish lines, ropes and collision. Another limitation is the consideration of preventing the turbine system from crashing into the keel during the 180 degrees transition. The distance between turbine blades and hull is determined as $15 \%$ of the diameter, at least. Increasing the distance is considered in the results as to whether it increases the appendage resistance potential in the system, and the potential entanglement of fish lines, etc. The most important component in the MCT system is the alternator, where the rotation induced by flow through the blades is converted into electrical energy. A Permanent Magnet Generator (PMG) type alternator is used in the present system. This type of alternator is used to charge the batteries to store energy, especially when keeping the number of revolutions constant is not possible. The greatest advantages of this type of alternator are high efficiency, high power, low inertia and simple construction. The alternator used is designed to be capable of rotating 180 degrees, together with the system. The system 
is positioned on the vessel according to the given information and limitations, and CFD analyses are performed on the geometry, with the aim of yielding the most approximate solutions. CFD analyses of the finalized initial design turbine geometry are investigated through performance aspect and ANSYS [35] is used for the detailed design.

\section{CFD Analysis}

Most of the engineering problems cannot be solved analytically because of complexity in the geometry, but solutions can be obtained through dividing the geometry into a finite number of volumes. Turbine geometry, hydrodynamic flow and resistance characteristics, are analyzed using CFD by finite volume method. Rotation, through a specified number of rotations, is defined for the turbine blades, and then the thrust and torque of the blades, and the resistances acting on the system components within flow, are calculated. At the initial design stage, in order to make a comparison between the performance of the single blade design using MBEM and performance predictions, calculations are made to include both for a) only the blades and b) the vessel and the system. Moreover, considering the potential during wind sail of a sailboat with 5 degrees leeway angle relative to vessel longitudinal axis, on average, calculations are done for uniform flow with 5 degrees flow angle, and the results are given for comparison.

\subsection{Construction of calculation geometry and flow volume}

Following the design of the turbine blades, flow volume is developed using Ansys Design Modeler. Comparison of calculations using MBEM, including solving all the system components together with the vessel, and those of both final performance and resistance data are done as well as flow volumes for two different geometries are generated. System geometry, consisting of hull, turbine and skeg, used in the CFD analyses is shown in Figure 15. At this point, calculation of vessel resistance is out of scope for the present study. However, in calculation of the turbine performance and resistance data, to take into consideration hull-turbine interference, hull geometry is included in flow volume, but the boundary conditions are built only to maintain the specified interference. In other words, analyses are performed to not extend the calculation flow period around the hull in detail, and similar to hull resistance analyses, they are not modeled for 'when needed'.

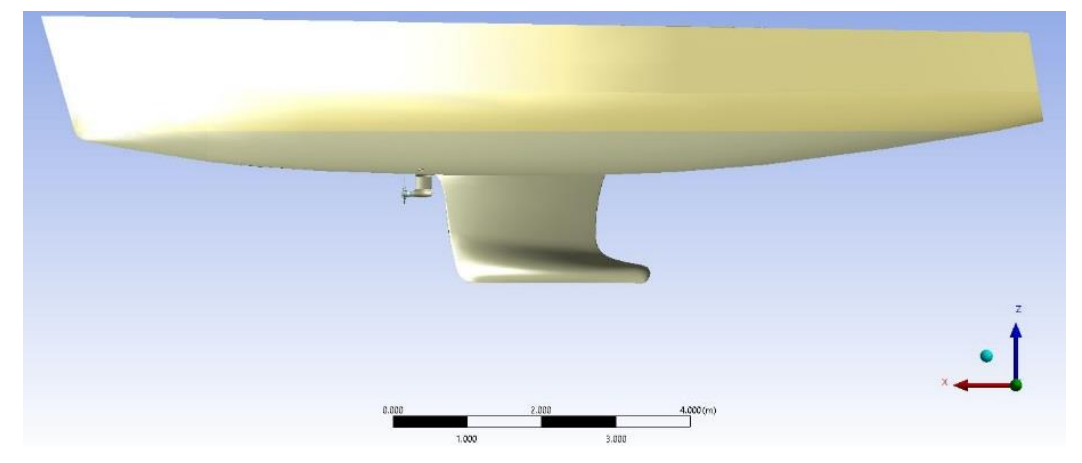

Fig. 15 Geometries of hull, turbine and skeg used in CFD analyses

\subsection{Grid generation and determination of boundary conditions}

For the single blade analysis: Hub geometry is extended until the trailing end surface. Element size on blade is $0.5 \mathrm{~mm}$. On the hub element, sizes increase to $2 \mathrm{~mm}$. In the blade wake zone, element sizes are considered as $10 \mathrm{~mm}$. Number of boundary layer elements is considered as 15 . For detailed investigation of flow lines in the blade trailing edge, a 
condensation zone of $2000 \mathrm{~mm}$ is formed after the blade. The largest element size in solution volume is specified as $50 \mathrm{~mm}$. Boundary conditions, for the single turbine blade formed in turbine volume, are shown in Figure 16.

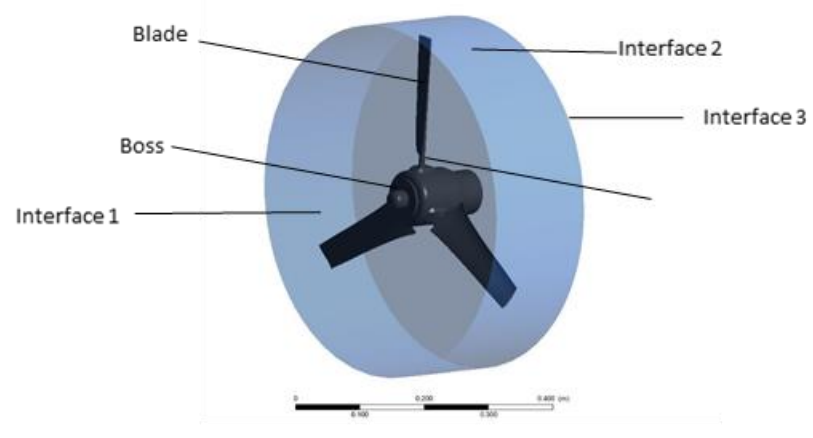

Fig. 16 Boundary conditions in turbine for a single blade

Analysis of the system, as a whole: On blade leading and trailing edges, element sizes on the blade are $0.5 \mathrm{~mm}$. The largest element size on the blade and hub is $3 \mathrm{~mm}$ and the largest element size on the pod is also specified as $3 \mathrm{~mm}$. On the hull body, element sizes are determined according to surface gradient, and the largest element size on the pod is $500 \mathrm{~mm}$. During the solution, the hull is used to direct flow. Therefore, boundary layer elements are not formed on the hull. On the turbine pod, blades and hub, 10 rows of boundary layer elements are formed. After the turbine pod, $1500 \mathrm{~mm}$ of wake zone is defined. Element sizes in the zone are $10 \mathrm{~mm}$. CFD analyses of the solution mesh structure for the system are shown in Figure 17 and the boundary conditions formed in turbine volume are shown in Figure 18.

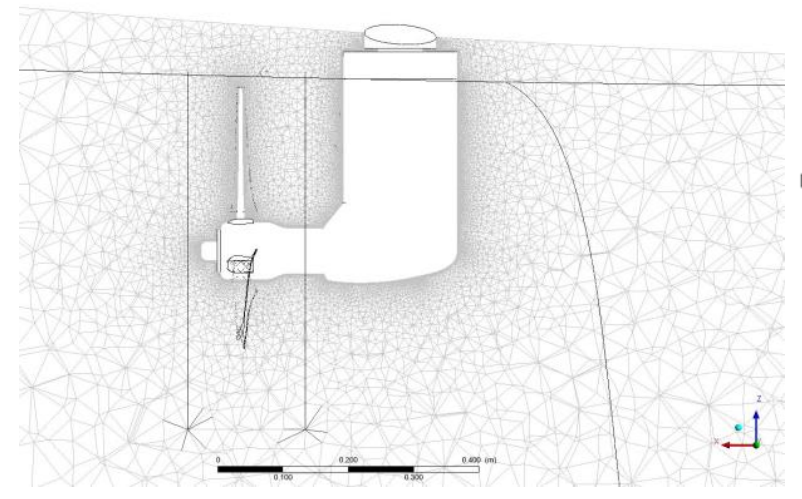

Fig. 17 Solution mesh structure in turbine Fig. 18 Boundary conditions for turbine with with the system for CFD analyses

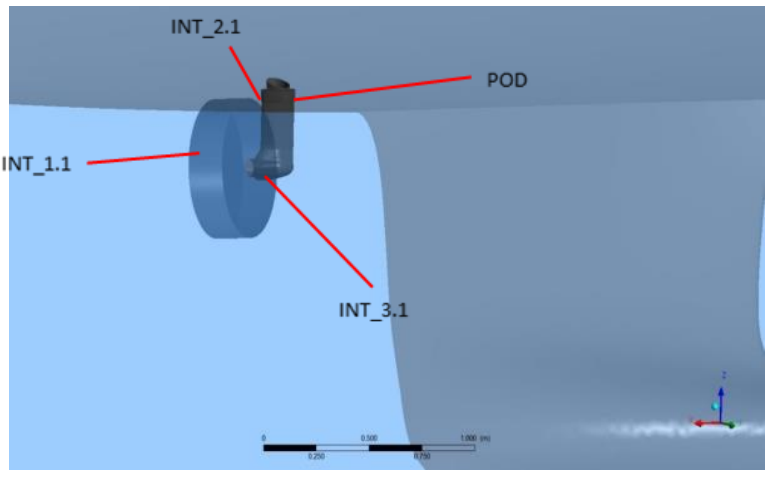

the system for CFD analyses 
At first, analyses are performed at various flow velocities and turbine speeds for only the single turbine blade and the whole system. Pressure distributions are obtained at blade face side and blade back side. In Figure 19, pressure distributions at $3.1 \mathrm{~m} / \mathrm{s}$ flow velocity and 340 rpm turbine speed are shown for the single blade, face side (a) and back side (b).
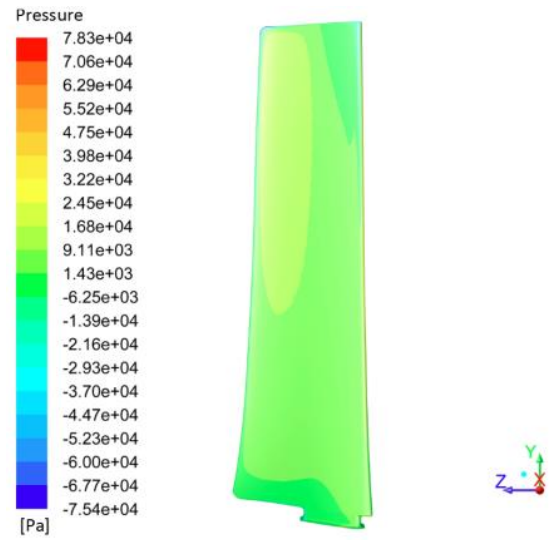

Fig. 19 (a) Pressure distributions on face side of the single blade $(3.1 \mathrm{~m} / \mathrm{s}$, $340 \mathrm{rpm})$

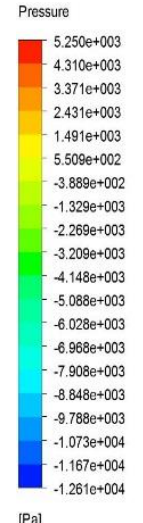

[Pa]

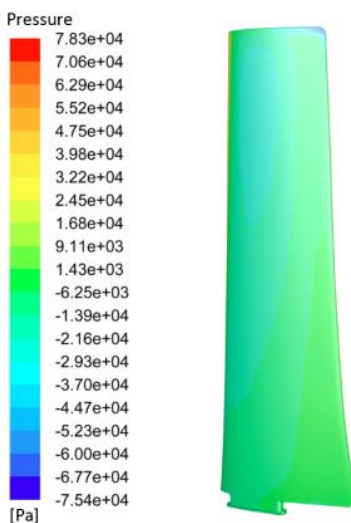

Fig. 19 (b) Pressure distributions on back side of the single blade $(3.1 \mathrm{~m} / \mathrm{s}$, $340 \mathrm{rpm})$

Fig. 20 Pressure distributions over the system at off state $(3.1 \mathrm{~m} / \mathrm{s})$

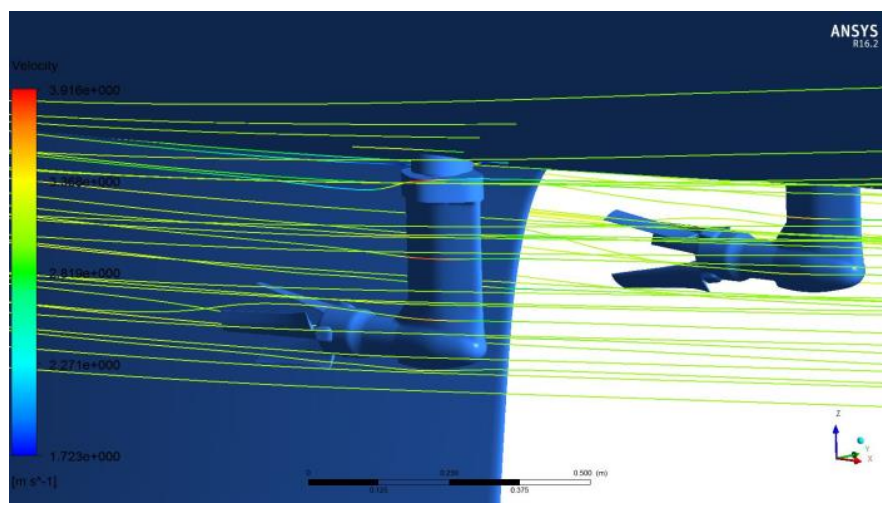

Fig. 21 Streamlines of the system at off state $(3.1 \mathrm{~m} / \mathrm{s})$ 
Closed position resistance values can be reduced through pressure drop at shaft center line as seen in Figure 20 illustrating the view from analyses of the turbine blades at closed position of pressure distributions over the system at off state $(3.1 \mathrm{~m} / \mathrm{s})$ and hydrodynamic design improvements, as seen in Figure 21 illustrating the views from analyses of the turbine blades at closed position of the system streamlines at off state $(3.1 \mathrm{~m} / \mathrm{s})$. However, geometrical expansion in the region of the turbine cannot be reduced further due to the influence of the vertical shaft, the shaft bearing in the pod and the pod wall thickness.

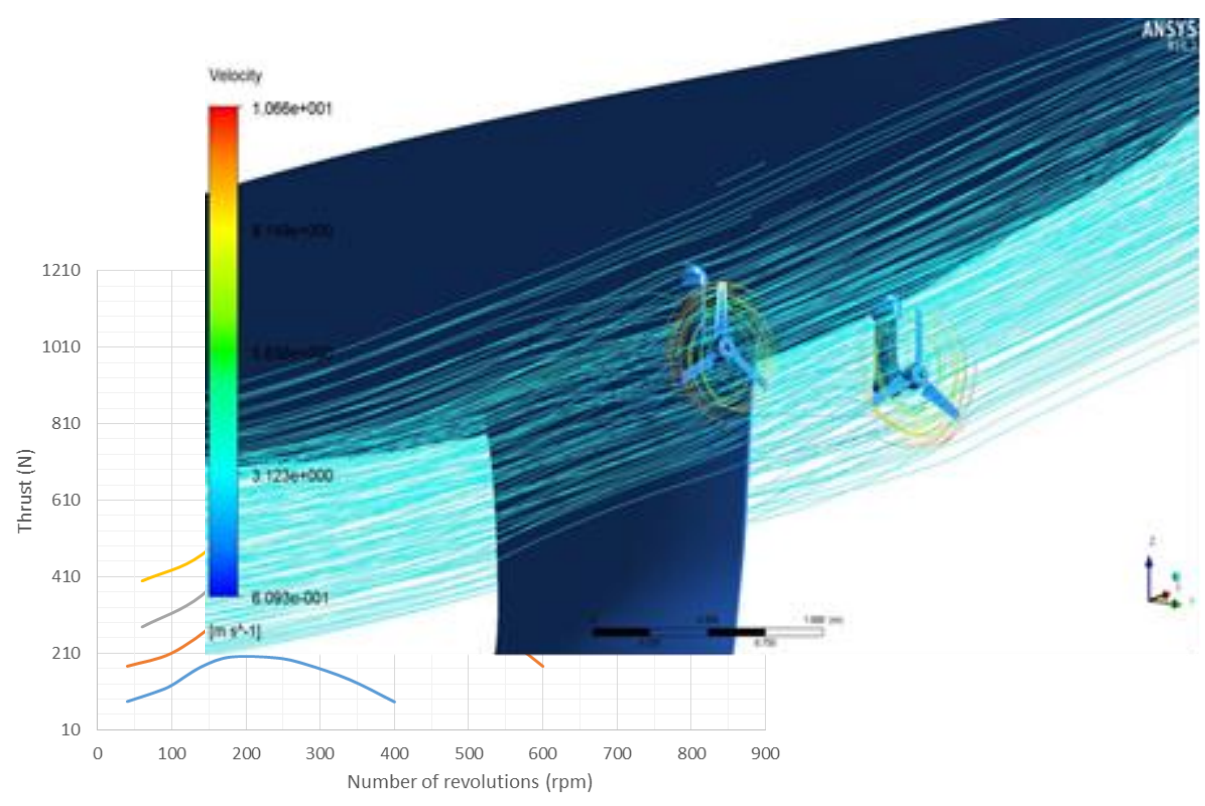

Fig.22 Streamlines of the system at on state $(3.1 \mathrm{~m} / \mathrm{s})$

To compare thrust and torque values, the MBEM results used at initial design stage and the CFD method results, analyses are performed in open water conditions and for just a turbine; are performed. And thrust and torque values are shown for comparison, in Figure 23 and Figure 24, respectively. Section drag and lift coefficients in 2D flow are used in MBEM, however, the viscous effect at the boundary layer and the dynamics of 3D flow are not regarded. When these effects are taken into account, especially on the section at low resultant velocities, in other words, with a low blade number of revolutions, then the difference is observed to be higher. On the other hand, the effect of the viscosity on the result is reduced and, rather, a decrease in error is observed where the section geometry hydrodynamic design effect is increased with high resultant velocities. This situation should be considered in the design of similar systems using MBEM.

Comparison of the system at various flow velocities using CFD results in terms of thrust is shown in Figure 25, and in terms of torque is shown in Figure 26.

A sailboat cannot sail on a straight route at most, because of wind direction, planned route, sail angle, etc. Leeway angle is defined as the angle between the straight line and headway line. CFD analyses are performed to study for vessel progressing at 5 degrees leeway angle and effect on turbine performance is investigated. Thereafter, the obtained results are compared to the results for uniform flow condition, as seen in Figure 27 in terms of the system thrust and in Figure 28 in terms of the system torque. 


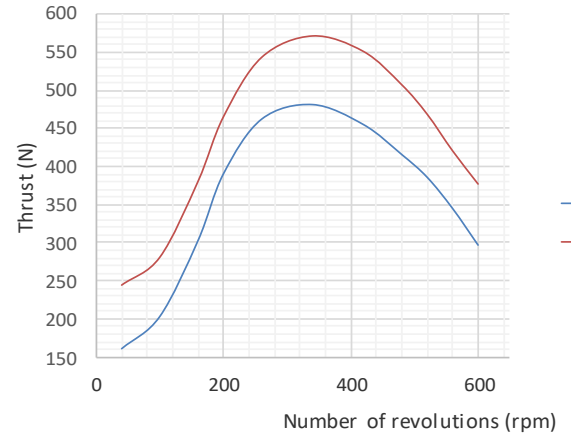

Fig. 23 Comparison in terms of thrust of the results obtained from CFD and MBEM for open water conditions

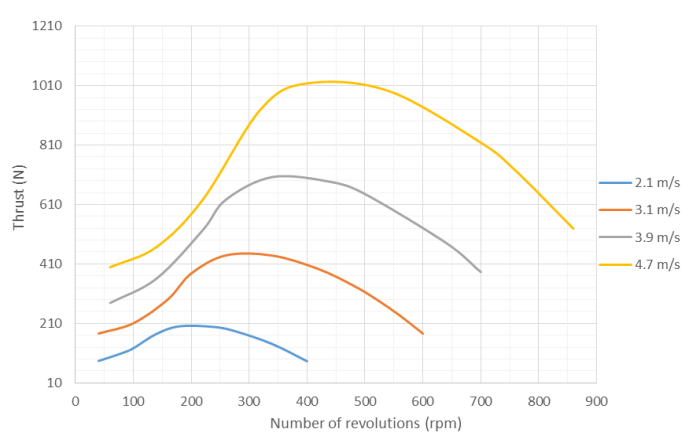

Fig. 25 A comparison in terms of thrust of the system results obtained from CFD for various flow velocities

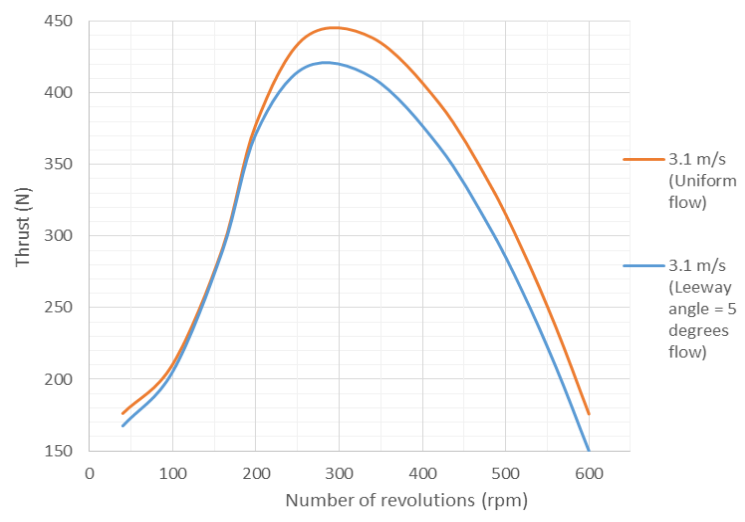

Fig.27 Comparison of results in terms of the system thrust obtained from CFD for uniform and leeway angle flow

For the vessel at engine sail, CFD analyses of the turbine at closed position (Position 1) and at 180 degrees position (Position 2) are performed to investigate the effect of the turbines on hull resistance. In the analyses performed at turbine off state, turbine resistance values calculated at the various flow velocities are shown in Figure 29. By applying curve fitting on this graph, added turbine resistance values at high velocities are predicted. Moreover, based on design requirements, total resistance of one turbine should not exceed 5\% of the hull resistance, at engine sail. As seen in Figure 29, 5\% of vessel resistance is shown and verification of design criteria is presented.
Fig. 24 Comparison in terms of torque of the results obtained from CFD and MBEM for open water conditions

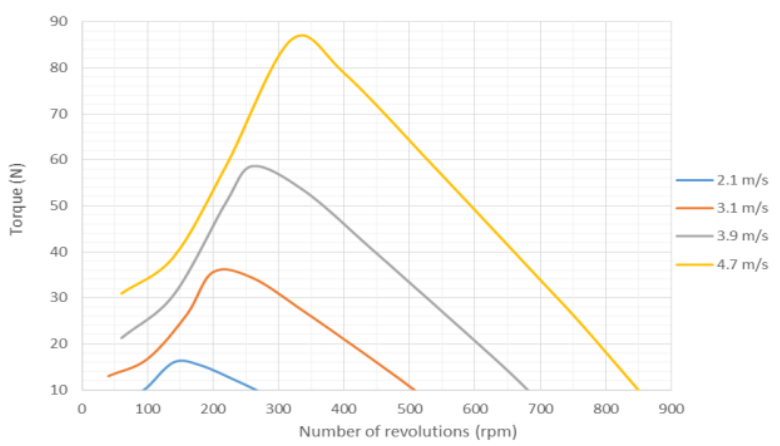

Fig.26 Comparison of results in terms of torque of the system obtained from CFD for various flow velocities

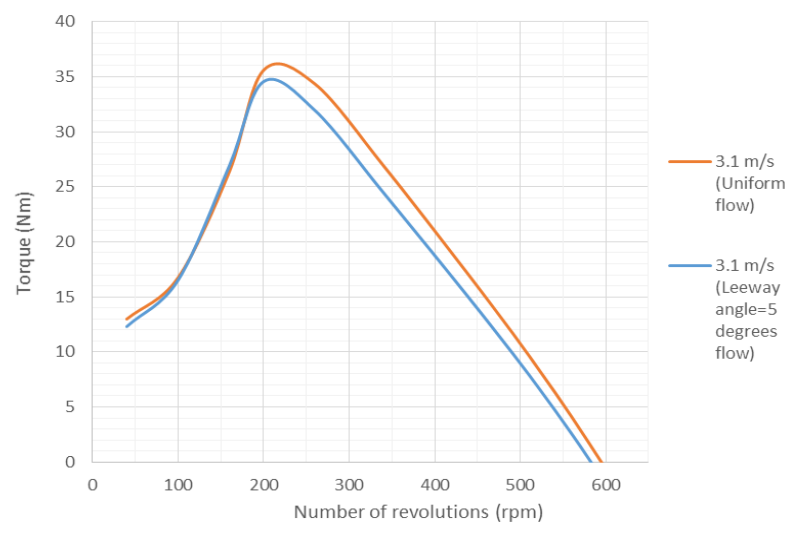

Fig.28 Comparison of results in terms of the system torque obtained from CFD for uniform and leeway angle flow 
After CFD analyses, as mentioned earlier, for evaluation of conformity for the alternator performance for the present system, calculations are performed. This is done through using four different alternator specifications, as can be seen in Table 6, selected from among renowned trademarks and longstanding worldwide manufacturers.

Table 6 Alternator characteristics of four different trademarks

\begin{tabular}{|c|c|c|c|c|c|}
\hline Alternator & $\begin{array}{c}\text { Max.rev. } \\
(\mathrm{rpm})\end{array}$ & $\begin{array}{c}\text { Max. Torque } \\
(\mathrm{Nm})\end{array}$ & $\begin{array}{c}\text { Weight } \\
(\mathrm{kg})\end{array}$ & $\begin{array}{c}\text { Max. } \\
\text { Power (W) }\end{array}$ & $\begin{array}{c}\text { Efficiency } \\
(-)\end{array}$ \\
\hline Alternative 1 & 1500 & 15.6 & 14 & 2400 & $95 \%$ \\
\hline Alternative 2 & 600 & 55 & 19.7 & 2850 & $87 \%$ \\
\hline Alternative 3 & 1200 & 25.8 & 21 & 3000 & $91 \%$ \\
\hline Alternative 4 & 1500 & 31.5 & 13 & 3775 & $83 \%$ \\
\hline
\end{tabular}

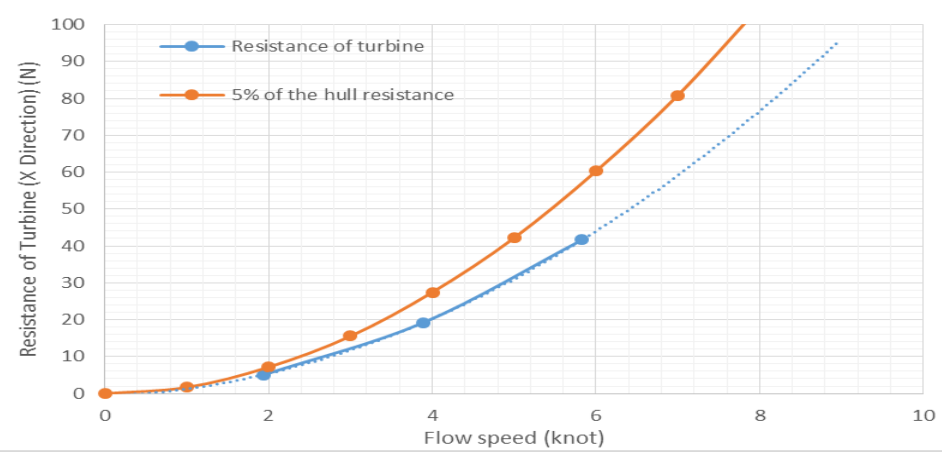

Fig. 29 Turbine resistance values for various flow speeds (at off state)

As seen in Table 6, alternators run at various nominal speeds and torques and only one turbine is present to prime all the alternators given. The critical point is that, given the power obtained from the turbine is always the same, the most convenient alternator for the corresponding optimum speeds and for torque values output by the turbine is determined. So, turbine speed should be determined with convenient speed reduction or elevation ratio regarding the alternator. Current information on alternators is manufacturer supplied with power-speed and torque-speed diagrams. These curves should be evaluated in conjunction with the performance curves; speed reduction or elevation ratios should be determined; and system operation speeds can be determined from the intersection points of the alternator torque curves and turbine torque curves at various speeds. Regarding the final determined ratio, using the alternator power-speed diagram, the projected power can be determined. The torque-speed diagram, showing the turbine performance characteristics is used. Curves obtained through CFD analyses and generated using interpolation and extrapolation methods for flow velocities in the range of $2.1 \mathrm{~m} / \mathrm{s}$ to $5.1 \mathrm{~m} / \mathrm{s}$ with step size of $0.1 \mathrm{~m} / \mathrm{s}$ are evaluated in Figure 30. Meanwhile, transmission efficiency, with resultant losses caused by mechanical friction in the transfer of power from turbine to alternator, is considered as 5\% and this contributed to the results. As seen in Figure 30, CFD results are shown in dashed line curves, and fitted curves are shown in solid lines. Maximum design velocity is considered as $5.1 \mathrm{~m} / \mathrm{s}$. First, the alternator manufacturer-supplied torque-speed diagram is placed on the graph shown in Figure 30, then the speed corresponding to the lowest velocity for effective power generation begins and then both the speed corresponding to the maximum design velocity of $5.1 \mathrm{~m} / \mathrm{s}$ and the alternator power at corresponding speeds are considered to determine the speed reduction/elevation ratio. For all the alternators, speeds at the intersecting turbine curves are read from the graphs, and the power at the corresponding speeds is obtained and evaluated. By increasing the reduction ratio, the power at the highest speed can be increased. However, increasing the ratio increases the speed and inversely proportional torque decreases. So, until then, the alternator starts to produce power over $2.5 \mathrm{~m} / \mathrm{s}$ flow velocity. Since, in this 
situation, design requirements are not meet, in determining the speed ratio, the first constraint is power production at $2.5 \mathrm{~m} / \mathrm{s}$ flow velocity, at the most. The second constraint is maximum power production at $5.1 \mathrm{~m} / \mathrm{s}$ flow velocity. The speed reduction/elevation ratio is determined under these circumstances. In Figure 31, resistance values obtained in the system at various turbine speeds are given for four alternator types, at each flow velocity ranging from $2.1 \mathrm{~m} / \mathrm{s}$ to $5.1 \mathrm{~m} / \mathrm{s}$. In Figure 32, alternator-turbine power coefficients are shown for four different alternators regarding to TSR.

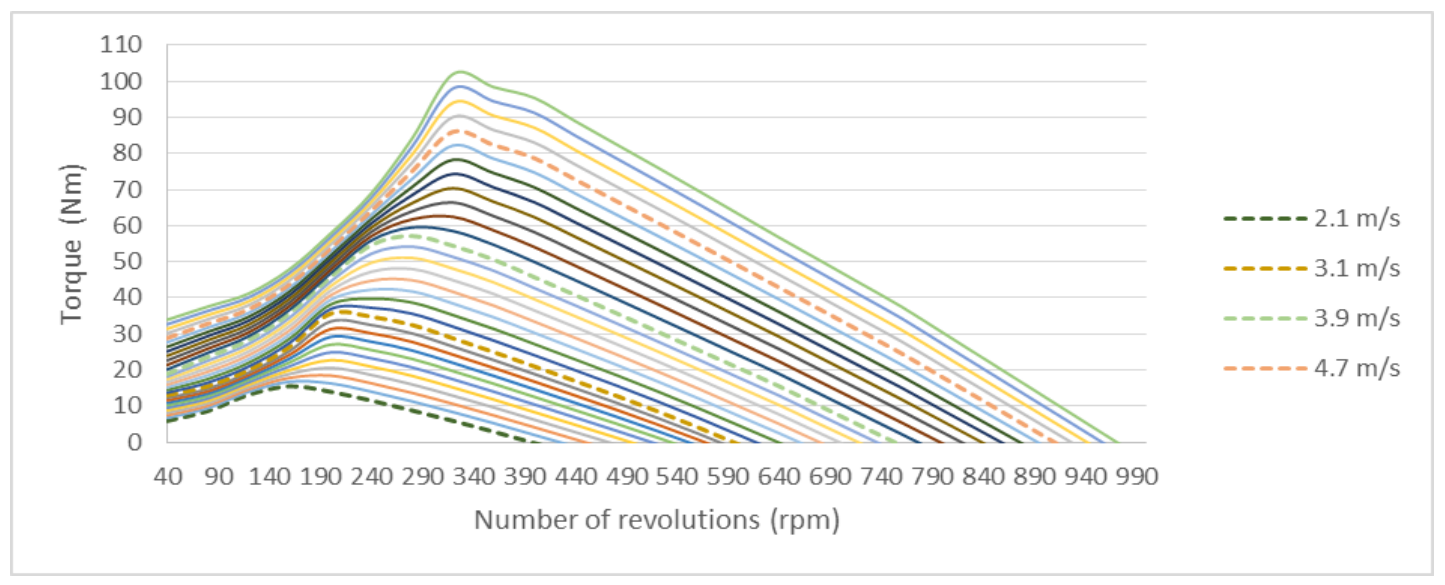

Fig. 30 Torque curves for various flow velocities of CFD results (in dashed lines) and fitted curves (solid lines), (in range of 2.1-5.1 m/s)

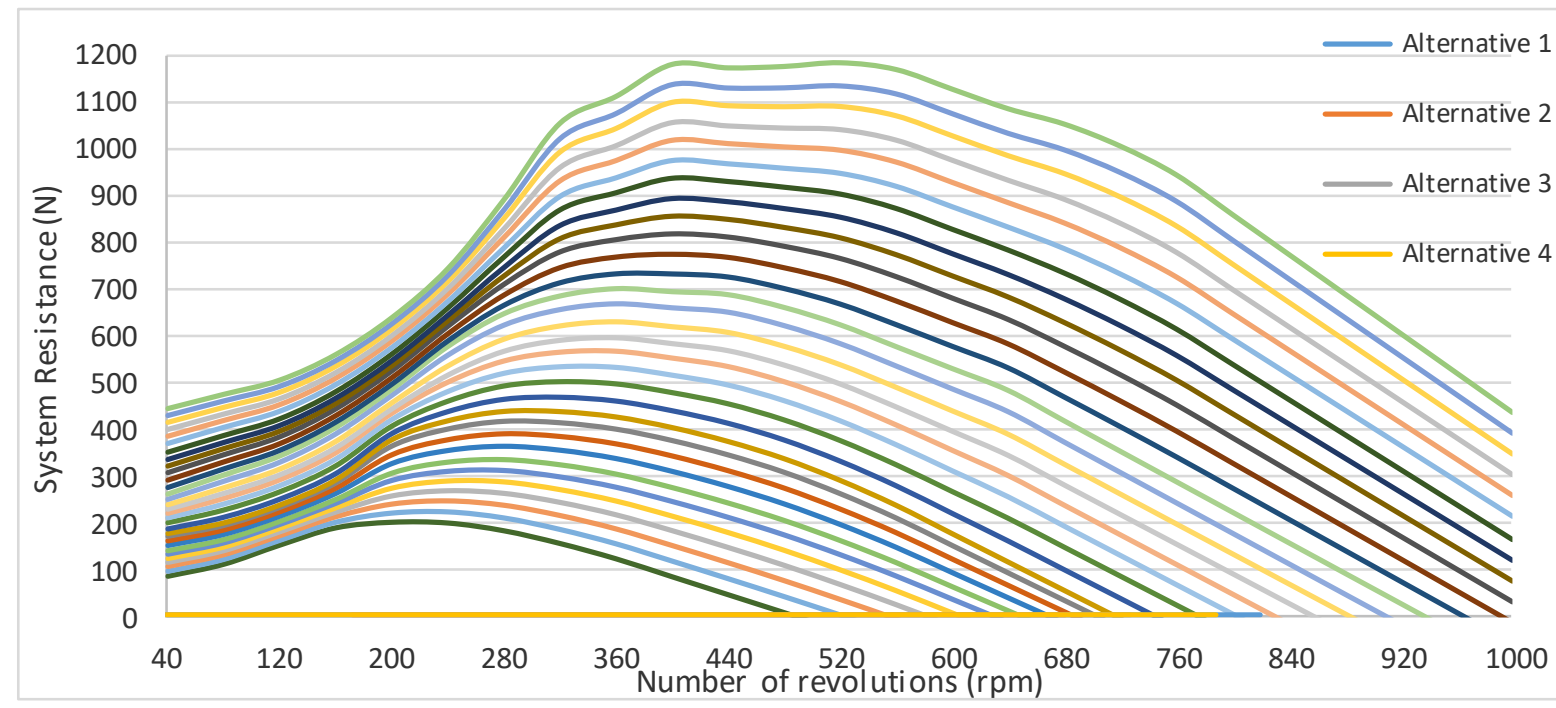

Fig. 31 Resistance values obtained in system at various turbine speeds for four alternator types at corresponding flow velocity

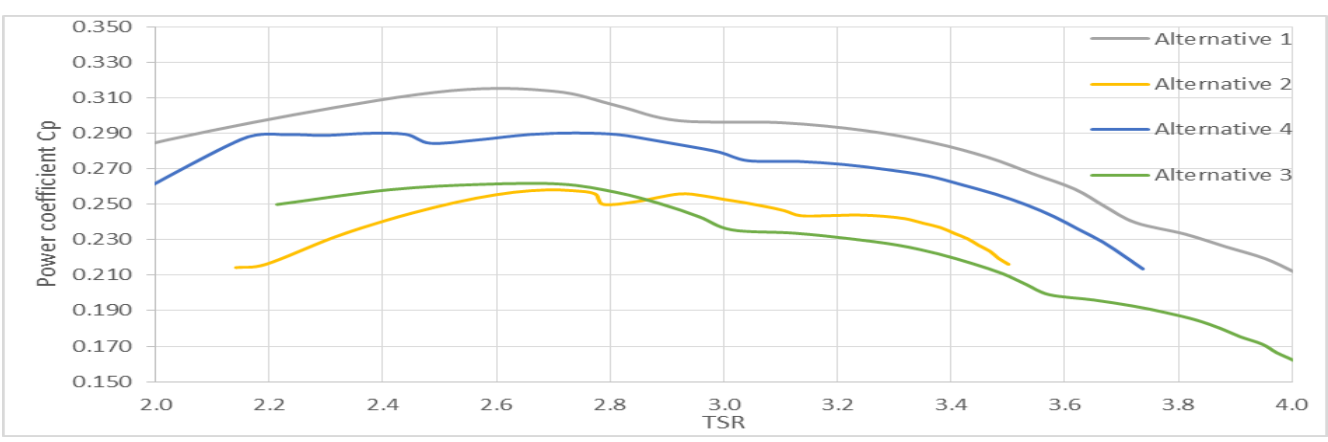

Fig.32 Alternator-turbine power coefficients regarding to TSR 
In conclusion, from studying Figure 31, Alternative 1, having less torque requirement, has lower resistance compared to the others. In Figure 32, the theoretical power relating to flow velocity for all alternatives is considered to be the same, and the power coefficient, determined from the ratio of alternator output power, is shown. On the other hand, Figure 32 shows that yet again the same model sustains the highest efficiency. As seen in Table 6, the same model has the lightest weight. Although Alternative 3 looks the lightest, this alternative is manufactured without a rotor shaft. So, considering the addition of rotor shaft weight, the weight of Alternative 3 exceeds Alternative 1. Moreover, the velocity requirement to start power production of $300 \mathrm{~W}$ at $2.5 \mathrm{~m} / \mathrm{s}$ seems to be exceeded for all the alternators. Considering all the situations, alternator selection is decided as Alternative 1. The resistance forces acting on the system with two turbines are calculated for Alternative 1 and compared to the resistance limitations, Figure 33. During sailing, added resistances, resulting from friction and thrust caused by running turbines should not exceed $25 \%$ of the hull resistance as can be seen in Figure 33. For further information refer to Alvar [32].

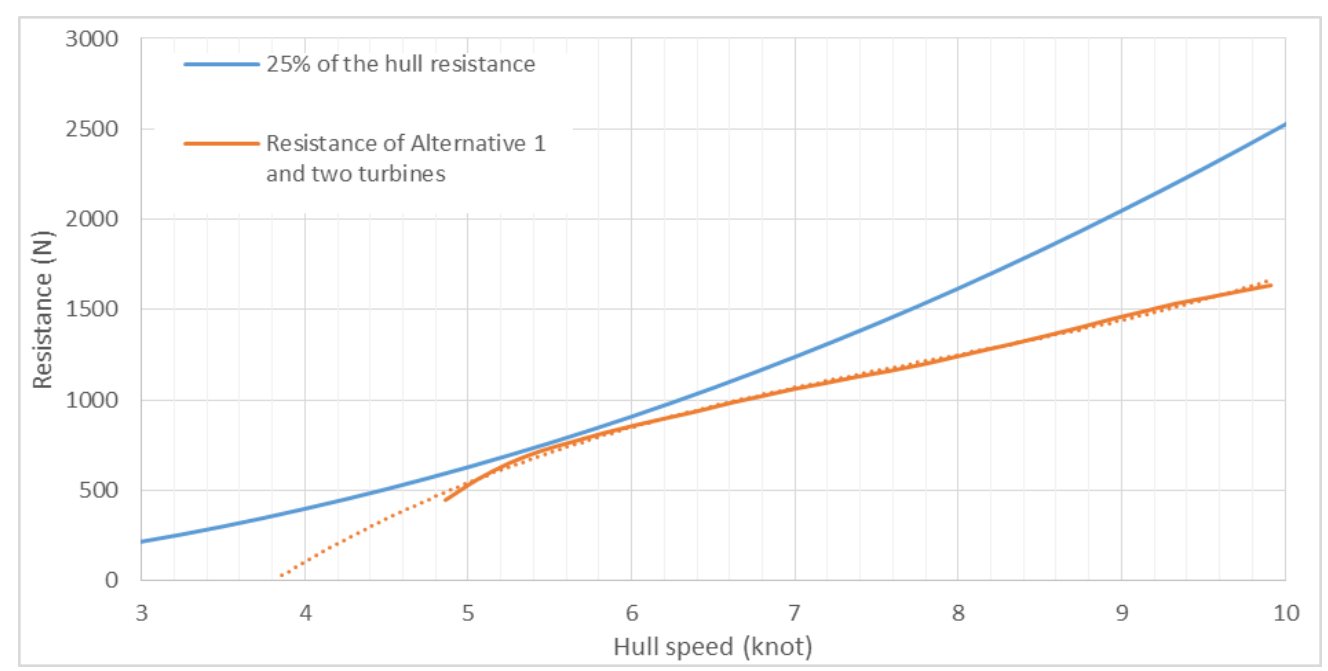

Fig.33 25\% of the total resistance of the hull, and resistance of the system with two turbines and Alternative 1 (during sailing)

\section{Conclusions and Recommendations}

In the present study, mechanical and hydrodynamic designs of MCTs are performed. In the wind-electric hybrid vessel concept, a sailboat is designed to set sail without a system/appliance consuming fossil fuel, and while at sail, the MCTs on the vessel are used to charge the vessel batteries by converting flow energy around the hull into electricity. At the start, the study is shaped by predicted design requirements and at each step verification is sought. Two turbines are placed on the vessel. To fulfill the requirements, the effect on vessel speed is minimized, while dimensioning the system for both at sail and sailing with engine on.

Turbines on the system have diameters of $500 \mathrm{~mm}$ since in the design requirements they are not to exceed $700 \mathrm{~mm}$. However, for larger turbine diameters, resistant forces acting on the system increase gradually, influencing the determination of the turbine diameters as 500 $\mathrm{mm}$.

The most convenient position for the system to be placed is determined by considering vessel interior layout, keel position, distance between turbine blades and hull, hull form 
curvatures at the point the system extends from the hull, and the ability of the system to rotate $180^{\circ}$.

The system produces $891 \mathrm{~W}$ power, and is above $850 \mathrm{~W}$ at design speed, and flow velocity/vessel speed is $3.1 \mathrm{~m} / \mathrm{s}$ (6 knot), which produces $398 \mathrm{~W}$, and is above $300 \mathrm{~W}$, at 2.5 $\mathrm{m} / \mathrm{s}$ flow velocity. Total weight of the system is $33 \mathrm{~kg}$. The largest contributors to system weight are the alternator components. In order not to exceed the weight limitation, for the mechanical equipment, mostly aluminum parts, resistant to sea water, are preferred. Besides, in the alternator selection, the above criteria are considered and the alternator choices are treated for performance, weight and size as a whole. In system mechanical design, sealants preventing water from the inlet into the hull are used, and risk is minimized by placing a secondary sealant behind the first. Thus, a system meeting the design requirements is presented.

For further study, manual operation of $180^{\circ}$ rotation can be converted into automation by controlling a servo motor system. On the other hand, the operation of the mechanical system, strength of materials used, performance etc. can be improved by inspections and tests in field on the actual system.

Since an electronic controller circuit for power and charge is already built in the REPSAIL project power management system, further information is not given here. Alternator specifications, alternator speeds for various flow velocities, and power output data at corresponding speeds, for successful power output control, are given by the project partner (Maritime University of Szczecin), supplier of the system. The power control unit operates to maintain power always at the highest level, defined as Maximum Power Point Tracking method (MPPT), and controls the power to charge the batteries.

The proposed system can be installed on sail boats which also make use of renewable sources such as wind and/or solar and store and use accumulated energy when needed. This system is user friendly, innovative, and offers more power and efficiency, and is longer lasting, compared to solar and wind technologies. It is the only one on earth with design features and power output aspects. However, outboard applications of low power are present. It can be concluded that the system can be converted into a commercial product. Further studies, adding an electronic controller at the alternator output to regulate charge, and using composite construction materials to reduce total weight to improve the system, can be performed.

As a result, a user friendly, innovative product for sail boats is proposed. It offers more power and efficiency, is longer lasting compared to solar and wind technologies, makes use of renewable sources such as wind and/or solar, and stores and uses accumulated energy when needed.

\section{ACKNOWLEDGEMENTS}

This study is supported under the International Support program ERA-NET TRANSPORT in which Milper Propeller Technologies Inc. is involved, with the project name "Development of Zero Emission Renewable Energy Producing Hybrid Biocomposite Sail Yacht Concept”. 


\section{Nomenclature}

\begin{tabular}{|c|c|c|c|}
\hline$a$ & :Axial flow factor & $r$ & :Radial direction \\
\hline$a^{\prime}$ & :Angular induction factor & $T$ & :Torque $(\mathrm{Nm})$ \\
\hline$B$ & :Blade number & $\beta$ & :Blade section pitch angle (degree \\
\hline$c$ & :Chord length (m) & $\lambda_{r}$ & :Tip speed ratio \\
\hline$C_{L}$ & :Section lift coefficient & $\eta$ & :Efficiency \\
\hline$C_{D}$ & :Section drag coefficient & $\rho$ & :Fluid density $\left(\mathrm{kg} / \mathrm{m}^{3}\right)$ \\
\hline$C_{P}$ & :Power coefficient & $\sigma^{\prime}$ & :Local rigidity factor \\
\hline$C_{P r}$ & :Pressure coefficient & $\theta$ & :Tangential coordinate) \\
\hline$D$ & :Drag & $\Omega$ & :Angular velocity $(\mathrm{rad} / \mathrm{s})$ \\
\hline$F_{x}$ & $\therefore$ Axial force(thrust) $(N)$ & $\omega$ & :Wake angular velocity $(\mathrm{rad} / \mathrm{s})$ \\
\hline$L$ & $\therefore \operatorname{Lift}(N)$ & $r_{h}$ & :Turbine hub radius $(\mathrm{m})$ \\
\hline$P$ & :Power $(W)$ & $\alpha_{D}$ & :Angle of attack (degree) \\
\hline$R$ & :Blade tip radius $(m)$ & & \\
\hline$Q$ & :Tip unload factor & & \\
\hline
\end{tabular}

\section{REFERENCES}

[1] R. Yemm, D. Pizer, R.C. Retzle, R., Henderson "Pelamis: experience from Concept to connection", Philosophical Transactions of the Royal Society A: Mathematical, Physical and Engineering Sciences, 370:1959: 365-380. (2012).

[2] F. Grasso, "Design and Optimization of Tidal Turbine Airfoil", presented at the 29th AIAA Applied Aerodynamics Conference, 27-30 June, Honolulu, HI, USA. AIAA2011-3816, (2011). https://doi.org/10.2514/6.2011-3816.

[3] D.M. Somers and M.D. Moughmer, "Theoretical Aerodynamic Analyses of Six Airfoils for Use on Small Wind Turbines", National Renewable Energy Laboratory, NREL/SR-500-33295 (2002).

[4] R.M. Ahmed, "Blade sections for wind turbine and tidal current turbine applications -current status and future challenges", International Journal of Energy Research, 36.829-844 \& Whiley Online Library DOI:10.1002/er.2912 (2012). https://doi.org/10.1002/er.2912.

[5] W.M.J. Batten, A.S. Bahaj, A.F. Molland and J.R. Chaplin, "Hydrodynamics of Marine Current Turbines", Renewable Energy, vol.31,pp.249-256,(2006a). https://doi.org/10.1016/j.renene.2005.08.020.

[6] W.M.J. Batten, A.S. Bahaj, Molland and J.R. Chaplin "Experimentally validated numerical method for the hydrodynamic design of horizontal axis tidal turbines", Ocean Engineering vol. 34, pp.1013-1020, (2007). https://doi.org/10.1016/j.oceaneng.2006.04.008.

[7] C.C. Chen, Y.D. Choi, and H.Y. Yoon, "Blade design and performance analysis on the horizontal axis tidal current turbine for low water level channel", presented at the 6th International Conference on Pumps and Fans with Compressors and Wind Turbines, Beijing, China, IOP Conf.Series: Materials Science and Engineering, DOI:10.1088/1757-899X/52/5/052020, (2013). https://doi.org/10.1088/1757-899X/52/5/052020.

[8] J.H. Lee, H.D. Kim, S.H. Rhee, I.R. Do, B.C. Shin, and M.C. Kim, "Computational and Experimental Analysis for Horizontal Axis Marine Current Turbine Design", presented at the Second International Symposium on Marine Propulsors smp.’11, Hamburg, Germany, (2011). 
[9] A.Mason-Jones , D.M. O’Doherty, C.E. Morris, T. O’Doherty, C.B. Byrne, P.W. Prickett, R.I. Grosvenor, I. Owenb, S. Tedds and R.J. Poole, "Non-Dimensional Scaling Of Tidal Stream Turbines", Energy vol.44, pp. 820-829. (2012). https://doi.org/10.1016/j.energy.2012.05.010.

[10] D. Wang and M. Atlar, "Experimental Investigation on Cavitation Performance, Noise Characteristics and Slipstream Wash of an Ocean Stream Turbine" presented at the World Maritime Technology Conference, IMarEST: London (2006).

[11] R. Evans, R. McAdam, M. Royle and L.i McEwen, “Optimum Geometry for Axial Flow Free Stream Tidal Turbine Blades", presented at the 10th EWTEC Eurpean Wave and Tidal Energy Conference, 3-5 September, Aalborg, Denmark, (2013).

[12] E. Fernandez-Rodriguez, T.J. Stallard and P.K. Stansby, "Experimental study of extreme thrust on a tidal stream rotor due to turbulent flow and with opposing waves", Journal of Fluids and Structures, vol. 51, pp.354361,(2014). https://doi.org/10.1016/j.jfluidstructs.2014.09.012.

[13] C. Frost , C.E. Morris, A. Mason-Jones, D.M. O’Doherty, T., O’Doherty, "The effect of Tidal Flow Directionality on Tidal Turbine Performance Characteristics”, Renewable Energy, vol. 78,pp. 609-620, (2014). https://doi.org/10.1016/j.renene.2015.01.053.

[14] D. Usar and S. Bal, "Cavitation Simulation on Horizontal Axis Marine Current Turbines", Renewable Energy, vol.80, pp.15-25, (2015). https://doi.org/10.1016/j.renene.2015.01.060.

[15] S.A. Kinnas and W. Xu, "Analysis of Tidal Turbines with Various Numerical Methods", presented at the 1th Annual MREC Technical Conference, Fall River, MA (2009).

[16] A rotor optimization tool for axial-flow wind and water turbines, HARB_Opt, http://nrel.github.io/HARP_Opt/, 15 Mayis 2016.

[17] D. Sale "HARP_Opt: An optimization Code For System Design of Axial Flow Turbines", presented at the Marine and Hydrokinetic Instrumentation, Measurement, \& Computer Modeling Workshop, Broomfield, CO, July 9-10,(2012).

[18] Drela, M.,"XFOIL: An Analysis and Design System for Low Reynolds Number Airfoils", presented at the Conference on Low Reynolds Number Airfoil Aerodynamics, University of Notre Dame, June, (1989). https://doi.org/10.1007/978-3-642-84010-4_1.

[19] D. Marten, G. Pechlivanoglou, C.N. Nayeri, and C.O. Pascherit, "Integration of a WT Blade Design Tool in XFOIL/XFLR5”, TU-Berlin HFI/ISTA, Berlin, Germany, https://www.researchgate.net/publication/275638785, (2010).

[20] W. J. Rankine "On the mechanical principles of the action of propellers" Transactions RINA 1865:6. ,(1865).

[21] H.Glauert, Airplane propellers. In Aerodynamic Theory, 4: 169-360. Springer, Berlin (1935). https://doi.org/10.1007/978-3-642-91487-4_3.

[22] M.Hansen, J., Sorensen, S. Voutsinas, N. Srensen, H. Madsen, "State of the art in wind turbine aerodynamics and aeroelasticity", Progress in Aerospace Sciences, vol.42, pp.285-330, (2006). https://doi.org/10.1016/j.paerosci.2006.10.002.

[23] K.Y., Maalawi and M.T.S. Badawy, "Direct method for evaluating performance of horizontal axis wind turbines, Renewable and Sustainable Energy Reviews, vol.5,pp. 175-190,(2001). https://doi.org/10.1016/S1364$\underline{0321(00) 00017-4}$

[24] M.O.L. Hansen, “Aerodynamics of Wind Turbines”, 2nd edition, Earthscan, London, UK. (2008).

[25] J.F. Manwell, J.G. McGowan, A.L. Rogers, "Wind Energy Explained - Theory, Design and Application”, John Wiley and Sons Inc., NY, USA,(2002). https://doi.org/10.1002/0470846127.

[26] T. Burton, D. Sharpe, N. Jenkins, E. Bossanyi, “Wind Energy Handbook”, John Wiley and Sons Inc., NY, USA, (2001). https://doi.org/10.1002/0470846062

[27] W.M.J. Batten, .S. Bahaj, A.F. Molland, J.R. Chaplin "The prediction of Hydrodynamic performance of Marine Current Turbines", Renewable Energy, vol.33, pp.1085-1096,(2008). https://doi.org/10.1016/j.renene.2007.05.043. 
[28] J. I. Whelan, J. M. R. Graham and J.Peir, "A free-surface and blockage correction for tidal turbines", Jornal of Fluid Mechanics, vol.624, pp. 281-291,(2009). https://doi.org/10.1017/S0022112009005916.

[29] S.M.D. Widjanarko, "Steady Blade Element Momentum Code for Wind Turbine Design Validation Tool", Sustainable Energy Technology, Universiteit Twente, Enschede, Netherlands, (2010).

[30] D. Sale, "Hydrodynamic optimization method and design code for stallregulated hydrokinetic turbine rotors" presented at the 28th ASME International Conference on Ocean, Offshore and Arctic Engineering, May31-June 5,(2009).

[31] Sale, D., HARP_Opt: An optimization code for system design of axial flow turbines, Marine and Hydrokinetic Instrumentation, Measurement, \& Computer Modeling Workshop Broomfield, CO July 910,(2012).

[32] http://www.solidworks.com/(06.05.2016)

[33] http://www.flexofold.com(06.05.2016)

[34] M. Alvar, "Horizontal Axis Marine Current Turbine Design for Wind-Electric Hybrid Sailing Boat" MSc Thesis, Yıldız Technical University, Istanbul, 2016 (in Turkish).

[35] http://www.ansys.com/ (06.05.2016)

Submitted: $\quad$ 20.08.2016 $\quad$ Serkan Ekinci, corresponding author, ekinci@yildiz.edu.tr

Yildiz Technical University, Naval Architecture and Maritime Faculty,

Accepted: $\quad$ 29.03.2017 $\quad$ Besiktas, İstanbul, Turkey.

Mustafa Alvar, mustafa.alvar@milper.com.tr

Milper Propeller Technologies Inc., Pendik, Istanbul, Turkey. 